ISSN: 0514-7336

DOI: http://dx.doi.org/10.14201/zephyrus20198379105

\title{
UNA NUEVA VÍA FUNERARIA EN COLONIA PATRICIA (CÓRDOBA). EL SEPULCRETUM DE LLANOS DEL PRETORIO
}

\section{A new funerary road in Colonia Patricia (Córdoba). The sepulcretum of Llanos del Pretorio}

\author{
Desiderio Vaquerizo Gil*, Ana B. Ruiz Osuna* y Manuel Rubio Valverde** \\ *Dpto. de H. a del Arte, Arqueología y Música. Facultad de Filosofía y Letras-UCO. Plaza del Cardenal Salazar, \\ 3. 14071 Córdoba. Correo-e: aalvagid@uco.es; anaruiz@arqueocordoba.com. ID ORCID: 0000-0002-8604-958X; \\ 0000-0002-6189-1906 \\ ** Arqueólogo. Cl El Pecho, 41. 14816 Zagrilla Alta (Córdoba). Correo-e: manuelrubiovalverde@gmail.com
}

Recepción: 10/09/2018; Revisión: 20/02/2019; Aceptación: 14/03/2019

\begin{abstract}
Resumen: Damos a conocer con este trabajo, en absoluta primicia, un nuevo sepulcretum romano excavado recientemente en la necrópolis septentrional de Córdoba (España); un espacio bien planificado desde el punto de vista topográfico, que se organiza en recintos pareados con módulo predominante de $12 \times 12$ pies romanos, abiertos a una o más vías funerarias, delimitados por cipos de piedra -dos de ellos con indicación de las mensurae sepulcri-, y, en ocasiones, cerrados mediante muros de mampostería, con puertas de acceso en su fachada y ustrinum en su interior. La necrópolis fue sellada por una riada, lo que ha permitido recuperar la mayor parte de los enterramientos -52 cremaciones y 11 inhumaciones infantiles- intactos e in situ, con cronologías centradas en los comedios del s. I d. C. Todos estos materiales, procedentes de un seguimiento arqueológico vinculado a la construcción de un nuevo edificio de viviendas, están siendo estudiados en el marco de un proyecto multidisciplinar con investigadores de diferentes universidades -numismática, vidrio, cerámica, antropología, epigrafía, paleopaisaje, fauna, etc.-, del que este artículo constituye un primer avance.

Palabras clave: Córdoba romana; funus; topografía funeraria; vías sepulcrales; mensurae sepulcri; recintos.

Aвstract: In this paper we present a new Roman sepulcretum which has recently been dug out in the northern necropolis of Córdoba (Spain): a well-planned space from a topographic point of view, organised into paired enclosures with a predominant module of $12 \times 12$ Roman feet opened to more than one funeral routes delimited by milestones - two of them belonging to mensuare sepulcri- and sometimes closed through masonry walls with access doors in its facade and an ustrinum inside. The necropolis was sealed by a flood leading to recover the major part of the intact burials and in situ -52 cremations and 11 child burials-, with chronologies of the middle of the first century AD. All these materials, yielded by developer-led archaeology, are being studied within the framework of a multidisciplinary project with researchers from different universities -numismatic, glass, ceramic, anthropology, epigraphy, paleolandscape, fauna, etc.-. This work is just one of the first advances.

Key words: Roman Córdoba; Roman funus; funerary topography; sepulchral roads; mensurae sepulcri; enclosures.
\end{abstract}

(C) Universidad de Salamanca

Zephyrus, LXXXIII, enero-junio 2019, 79-105 


\section{Antecedentes ${ }^{1}$}

El mundo funerario cordubense de época romana es, probablemente, uno de los mejor conocidos de Hispania. Han contribuido a ello los sucesivos proyectos de $\mathrm{I}+\mathrm{D}+\mathrm{i}$ desarrollados en la ciudad desde finales de los años 90 bajo la dirección de uno de nosotros -DVG- y la abundantísima bibliografía generada (Vaquerizo, 2013). Como resultado, sabemos que el caput Baeticae reprodujo con fidelidad extrema, y apenas matices locales muy difíciles de rastrear, los mismos procesos relacionados con la muerte que la Urbs. Es reflejo material de dicha circunstancia, en lo que se refiere a sus etapas altoy plenoimperial, una densa topografía conformada por viae sepulcrales sembradas de tumbas y monumentos de variada tipología; sepulcreta destinados a garantizar la memoria y un correcto paso al Más Allá de los que un día decidieron enterrarse en ellos, pero también a servir como escaparate público de la sociedad del momento, que rivalizó en posición, morfología, materiales y magnificencia de enterramientos, tumbas y monumenta, entendidos unos y otros como expresión última de su identidad gentilicia, su capacidad adquisitiva, su posición ideológica, su concepto de la escatología y, por supuesto, su vanitas.

Tales premisas, reforzadas por la alta densidad poblacional de la ciudad durante el Pleno Imperio ${ }^{2}$,

1 Este trabajo se inscribe en el marco del Proyecto de I + D + i PATTERn, concedido para el periodo 2016-2019 por el Ministerio de Economía y Competitividad, dentro del Programa Estatal de Investigación, Desarrollo e Innovación Orientada a los Retos de la Sociedad (Ref. HAR2015-68059C2-1-R). También, en el Proyecto de Excelencia del par Ciudades Romanas de la Bética. Corpus Vrbivm Baeticarvm -CVB I-, dirigido por J. M. Campos -Univ. de Huelva-. En una iniciativa sin precedentes en la ciudad, la investigación de la que aquí presentamos un primer avance ha sido patrocinada por los Amigos de la Arqueología Cordobesa, mecenas vinculados a la Asociación Cultural Arqueología somos todos, emanada del proyecto de cultura científica homónimo que sostiene el Grupo de Investigación Sísifo (PAIDI hum-236) de la Univ. de Córdoba, al que se adscriben los dos primeros firmantes.

2 Los últimos cálculos demográficos suponen para Colonia Patricia una población estable de entre 30.000 y 50.000 habitantes (Ventura y Gasparini, 2017: 176). concedieron al terreno extramuros un valor extraordinario, que exigió sin duda de una gestión rigurosa y en más de un caso generaría cierta especulación e incluso actos de evergetismo funerario. Baste recordar lo ocurrido en Sarsina (CIL I²/2123; CIL XI/6528; ILS/7846; ILLRP/662; cf. Ortalli, 1987: 157, n. 11), donde Horatius Balbus, en un acto de munificencia post mortem, cedió un terreno en favor de sus conciudadanos de menor poder adquisitivo -con exclusión expresa de auctorati, suicidas y quienes hubieren ejercido un trabajo infame-, a quienes asignaba un área de 10 pies de lado (Cenerini, 2005: 138; Alfayé, 2009: 186 y ss.; Vaquerizo, 2014: 213 y ss.). También el liberto C. Veienus Trophimus donó al municipium de Tolentinum una superficie de CC pedes in fronte por CCLXXXII pedes in agro destinada a resolver los problemas funerarios de los más indigentes (ILS/7847; Purcell, 1987: 36, n. 8).

Hasta la fecha conocíamos ya varias vías funerarias en Colonia Patricia (Vargas y Gutiérrez, 2004 y 2006; Ruiz Osuna, 2005 y 2007: 25-40; Vaquerizo et al., 2005; Liébana y Ruiz Osuna, 2006: 297-324; Ruiz Osuna, 2007, 2010 y 2014; Vaquerizo, 2010: 110 y ss.; Salinas, 2015)33 , e intuíamos que la ciudad debió reservar un espacio privilegiado en su flanco septentrional susceptible de ser parcelado según necesidad para otorgar honores funerarios y enterrar a sus hijos más ilustres, garantizar la memoria cívica colectiva y generar modelos ciudadanos en los que sustentar el prestigio y el liderazgo de sus élites (Melchor, 2006a: 116 y ss.; 2006b; Ruiz Osuna, 2007: 147). En este contexto tan particular, el hallazgo de un nuevo sepulcretum, especialmente bien planificado, en Llanos del Pretorio viene a confirmar una realidad rica y compleja que presentamos en primicia, pero en la que habremos de profundizar en próximos trabajos ${ }^{4}$.

3 También López Jiménez, A. (2006): Informe y Memoria. Parcela 4 del Plan Especial sc-2a, 06. Informe administrativo inédito. Córdoba y Molina, J. A. (2005): Informe Preliminar de la Actividad Arqueológica Preventiva en la cl Muro de la Misericordia esquina con cl Palomares (Córdoba). Informe administrativo inédito. Córdoba.

4 En el momento de entregar la versión definitiva de este trabajo preparamos un volumen monográfico sobre el conjunto que lo analizará con vocación integral desde una 


\section{El contexto}

Poco a poco van siendo identificados en Córdoba sectores y monumentos funerarios del s. I a. C., si bien en puridad seguimos sin conocer con precisión la ubicación de las áreas funerarias republicanas sensu stricto, que pudieron haber sido parcialmente amortizadas cuando la ciudad se amplía hacia el río (Ruiz Osuna, 2007: 124 y ss., planos 4 y 9); una idea que cobró más fuerza a partir del hallazgo de un posible monumento funerario de tipología no concretada bajo la cimentación de la media cavea del teatro de la colonia, para cuya construcción fue desmontado (Monterroso, 2002: 135 y ss.). No lejos se recuperó un fragmento del titulus sepulcralis sobre sillar en piedra de mina para encastrar de Bucca, esclavo/a de la familia Murria, fechado con cierta seguridad en época tardorrepublicana (Ruiz Osuna, 2007: 98-99 y 125, láms. 53-54).

De igual modo, los fustes jónicos con restos de estuco procedentes de la zona del Alcázar de los Reyes Cristianos podrían haber pertenecido a monumentos en forma de edicola de muy alta cronología (Ruiz Osuna, 2007: 105-106); y conviene no olvidar que los recintos conservados bajo los monumentos funerarios de la Puerta de Gallegos fueron construidos en la primera mitad del s. I a. C. (Murillo y Carrillo, 1999: 369; Murillo et al., 2002: 253), al igual que otro localizado en la avda. Ronda de los Tejares, con una cremación en urna de tradición indígena en su interior (Ibáñez, 1990: 176-181).

Parece, pues, que desde muy pronto las áreas funerarias de la Corduba romana se dispusieron inmediatas a las puertas urbanas ${ }^{5}$ y en torno a las vías; más en concreto la Corduba-Hispalis, al o; "Camino del Pretorio", al N; Corduba ab Emerita Augusta, al NE; y Augusta, al E y al s. Muy cerca de donde se

perspectiva marcadamente transversal e interdisciplinar, $y$ que seguramente será publicado en Italia [Vaquerizo, D. y Ruiz, A. (eds.): El sepulcretum de Llanos del Pretorio (Córdoba, España)].

5 Una circunstancia que no se cumple siempre de forma rigurosa. De hecho, algunos de los enterramientos más antiguos se localizan a buena distancia de las murallas, tal como se desprende de los hallazgos epigráficos y arqueológicos ( $c f$. al respecto Vaquerizo, 2010 o 2013). ubicó el sepulcretum en estudio apareció, de hecho, hace unos años un epígrafe (CIL II $2 / 7,699$ a) alusivo a una servitus viae del antiguo "Camino del Pretorio", que comunicaba Corduba con la zona minera del $\mathrm{N}$ incluido el distrito de Sisapo (Melchor, 2004: 113 y ss.), especializado en la producción de cinabrio (minium) y mercurio (argentum vivum) (Ventura, 1993: 56); un territorio que el futuro caput Baeticae se reservó en buena medida para su propia explotación (HEP 1, 1989: 309; Sillières, 1990: 791 y ss.; Ventura y Gasparini, 2017: 166 y ss.). Se explica así el hallazgo en la zona de varios tituli sepulcrales de individuos relacionados con las actividades mineras y metalúrgicas. Es el caso de Marcus Aerarius Telemachus, liberto y médico de la Societas Aerariorum ( $\left.C I L \mathrm{II}^{2} / 7,334\right)$, de cronología augústea, o de los tres libertos de la Societas Sisaponensis conmemorados en una misma inscripción hallada en el Tablero Bajo (CIL II $2 / 7,415 \mathrm{a})$. Todo ello parece confirmar la existencia de officinae de ambas societates en la zona, de fuerte vocación minera (Ventura, 1993), al tiempo que pone de nuevo en evidencia la coexistencia en los espacios suburbanos de enterramientos y focos de actividades nocivas; además de viviendas, horti, centros industriales y de transformación, basureros, etc.

También en las cercanías del Pretorio - cl Adarve- fue recuperado un fragmento de pulvinum labrado en piedra caliza y una cimentación de sillería correspondientes ambos a un gran altar monumental que podría haber pertenecido a $N$. Abullius Chriestus (CIL II $2 / 7,396)$, cuyo titulus sepulcralis remonta a la segunda mitad del s. I a. C. (Stylow, 1995: 224, n. 33); como el de su liberta Abullia Nigella ( $C I L \mathrm{II}^{2} / 7$, 397), del último tercio del s. I a. C., recuperado muy cerca, en el entorno de la Torre de la Malmuerta (Ruiz Osuna, 2007: 125 y ss.; Vaquerizo, 2010).

Un poco más el E -avda. de las Ollerías, n. ${ }^{\circ} 14-$ se excavó hace algunos años una estructura cuadrangular de sillares calizos interpretada como un monumento funerario y 16 enterramientos de cremación e inhumación, así como restos pertenecientes a posibles recintos; todos ellos se fechan en época altoimperial (Penco et al., 1993: 50; Marfil, 1997: 156). Más recientemente, hacia el final de la avda. de las Ollerías encontramos una batería de recintos 
de 12 x 12 pies, entre otros de mayor tamaño, señalizados algunos de ellos con mensurae sepulcri sobre cipos y estelas ${ }^{6}$ y ordenados a lo largo de una vía funeraria que se desarrollaba en sentido E-O ${ }^{7}$. Sorprende su lejanía con respecto a las murallas, si tenemos en cuenta la cronología augustea asignada a su primera fase. El mal estado de conservación general apenas permitió recuperar restos de las deposiciones practicadas en el interior de los recintos, amortizados por fases posteriores (Ruiz Osuna, 2007: 25-40).

Finalmente, el paisaje funerario inmediato ${ }^{8}$ queda completado en sus líneas básicas con los conjuntos de La Constancia, recuperado a solo un centenar de metros al N de Llanos del Pretorio, de conformación topográfica y ritual muy similar: siete recintos de planta rectangular dispuestos en torno a calles y espacios abiertos de uso funerario, con enterramientos dentro y fuera de las estructuras, en su mayoría de cremación y fechados entre los ss. I y il d. C. (Vaquerizo et al., 2005), y el de la cl Abderramán III-Centro de Salud Huerta de la Reina, donde se documentaron casi una decena de recintos funerarios abiertos a una vía con orientación $\mathrm{N}-\mathrm{S}$, de dimensiones indeterminadas. El sepulcretum, de la primera mitad del s. I d. C., sería reocupado años más tarde por enterramientos de inhumación que parecen convivir con usos industriales (Salinas, 2015).

Nos encontramos, en definitiva, ante uno de los sectores funerarios más tempranamente ocupados en la ciudad, más complejos y de mayor densidad, circunstancia que quizás sea preciso relacionar con el papel que las minas y la plata

6 Sobre el uso epigráfico de mensurae sepulcri en Hispania, vid. Vaquerizo y Sánchez, 2008.

7 López Jiménez, op. cit. n. 3.

8 No nos detenemos en otros hallazgos funerarios del entorno, como el bustum-ustrinum de Emacsa (Cánovas et al., 2006), el complejo funerario tardío de la Manzana Banesto [Salinas, J. M. (2004): Informe-Memoria del Plan Especial Manzana Banesto. SR-13. Córdoba e Informe-Memoria del Plan Especial Manzana Banesto. SR-13. Córdoba. Sector 1, Informes inéditos. Córdoba] o el posible monumentum de la P.D. 3.1. del Plan Parcial Renfe (Dortez, 2008). desempeñan en las primeras fases de la presencia romana en Corduba.

\section{Las circunstancias del hallazgo}

El sepulcretum de Llanos del Pretorio fue excavado en 2016 con motivo de un Seguimiento Arqueológico dirigido por uno de nosotros -MRV- en los n. ${ }^{\text {os }} 1$ y 3 de la avenida homónima, a unos $400 \mathrm{~m}$ del recinto amurallado de época romana (Fig. 1). El solar, con $820 \mathrm{~m}^{2}$ y planta casi cuadrada, había sido objeto ya, entre 2006 y 2008 , de una actividad arqueológica preventiva y un primer seguimiento?. Tales actuaciones pusieron en evidencia una secuencia estratigráfica que comenzaba en época romana altoimperial y alcanzaba el s. xx.

Ocho años más tarde, la Gerencia Municipal de Urbanismo de Córdoba requirió de un nuevo control arqueológico para poder continuar con las obras. Fue así como se detectó la vía funeraria, sellada por los limos de una arroyada confundidos con niveles geológicos en las intervenciones previas. Esta nueva actuación acabaría derivando en una excavación arqueológica con criterios estratigráficos y carácter de urgencia a finales de $2016^{10}$. A su conclusión se vació el solar hasta la cota de proyecto. De los restos estructurales solo se conservaron algunos cipos y un epígrafe, depositados en el Museo Arqueológico Provincial de Córdoba. El resto fue destruido.

9 Cf. Penco, F. (2007): Informe y Memoria de la Actividad Arqueológica Preventiva en Avenida Llanos del Pretorio $n^{\text {os }} 1$ y 3 (Córdoba) y (2008): Informe del Seguimiento Arqueológico en Avenida Llanos del Pretorio n. ${ }^{o s} 1$ y 3 (Córdoba). Informes administrativos inéditos. Córdoba.

10 Cuando hablamos de "excavación arqueológica con criterios estratigráficos" lo hacemos de manera consciente. Puede, de entrada, parecer una redundancia, pero no lo es. Desafortunadamente, en ciudades como Córdoba es fácil encontrar todavía ejemplos de intervenciones que no responden a los criterios especificados, sobre todo si fueron realizadas en el marco de la vorágine excavadora de los últimos 35 años. De ahí que consideremos oportuno y necesario especificarlo. 


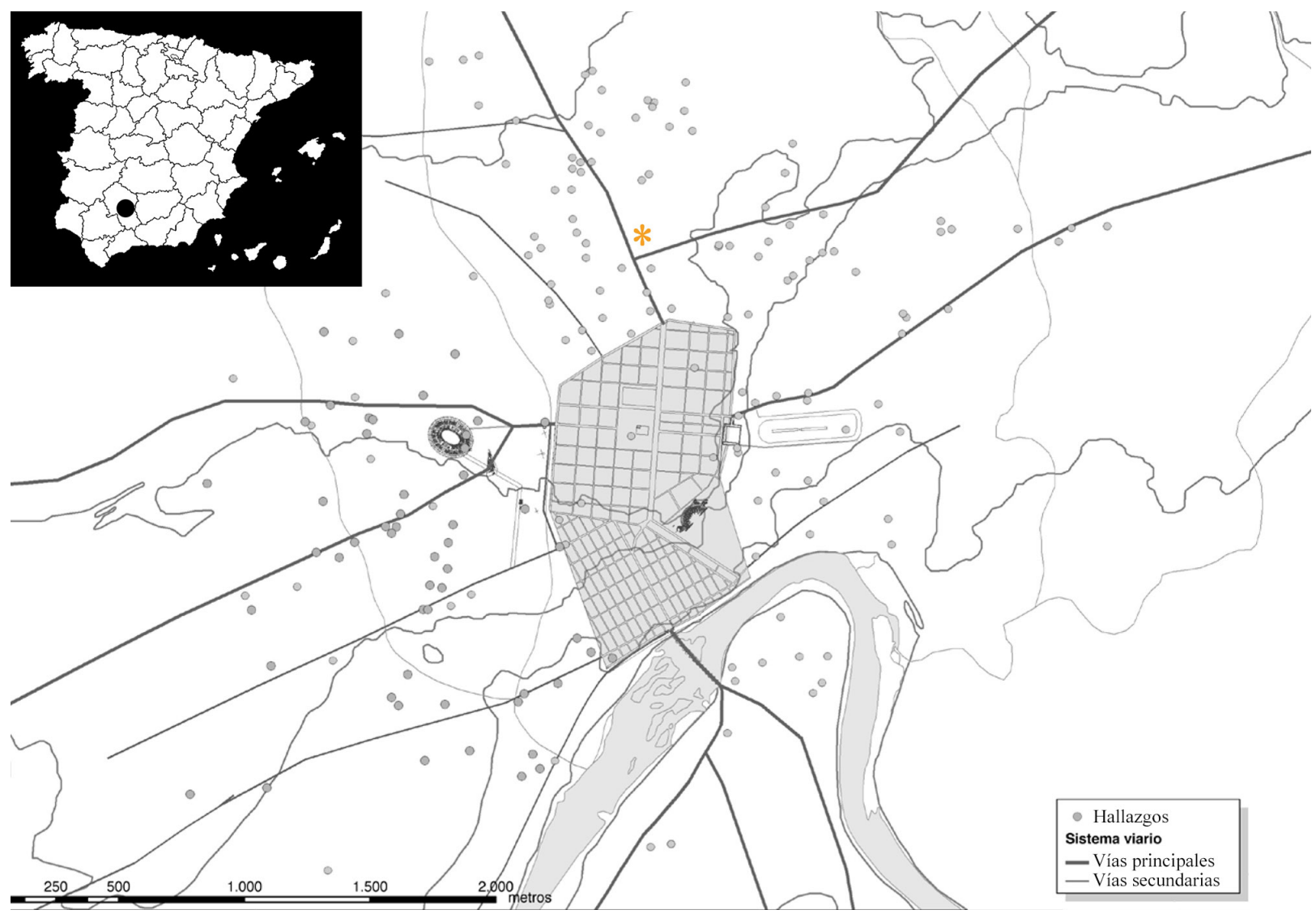

FIG. 1. Situación del sepulcretum con respecto al recinto amurallado de época romana.

\section{El sepulcretum}

El sector funerario excavado se estructuró a partir de una o varias vías ${ }^{11}$ de uso específicamente cementerial con orientación E-O. Recuperamos un tramo de $28 \mathrm{~m}$ de una de ellas, con 2,40 m de ancho -8 pies romanos- y firme de picadura de sillar que en algunos puntos alcanzaba los $0,40 \mathrm{~m}$ de potencia (Fig. 2). El hecho de que dicha pavimentación no penetrara en la batería meridional de recintos podría estar confirmando una planificación

11 Los recintos de la batería septentrional compartían linde trasera -en el caso del Recinto o, también medianeracon la parte posterior de una tercera línea de acotados bien documentada en la esquina nororiental y en el perfil $\mathrm{N}$ del solar, tal como se comprueba en los denominados Recintos o y p. Estos últimos darían fachada seguramente a una segunda vía de características similares a la excavada. inicial de la zona que habría dejado en reserva las zonas destinadas a acotados funerarios. En la septentrional, de hecho, la casuística es diferente, tal vez porque los lotes se establecieron en un momento posterior ( $c f$. infra). La vía debió discurrir perpendicular a las que salían de la Puerta Norte de la ciudad, conocida tradicionalmente como Porta Praetoria.

Abrían a la vía sendas series de recintos no del todo simétricos (Fig. 3), lo que sugiere un crecimiento más complejo y quizás diacrónico del que dejaría entrever una lotización rigurosa y simultánea. Obviamente, entra dentro de lo posible que intervinieran en su trazado condicionantes de tipo orográfico, de propiedad de la tierra, o simplemente de sucesión cronológica. En su interior fueron recuperados 67 enterramientos, 2 de ellos de perros: 


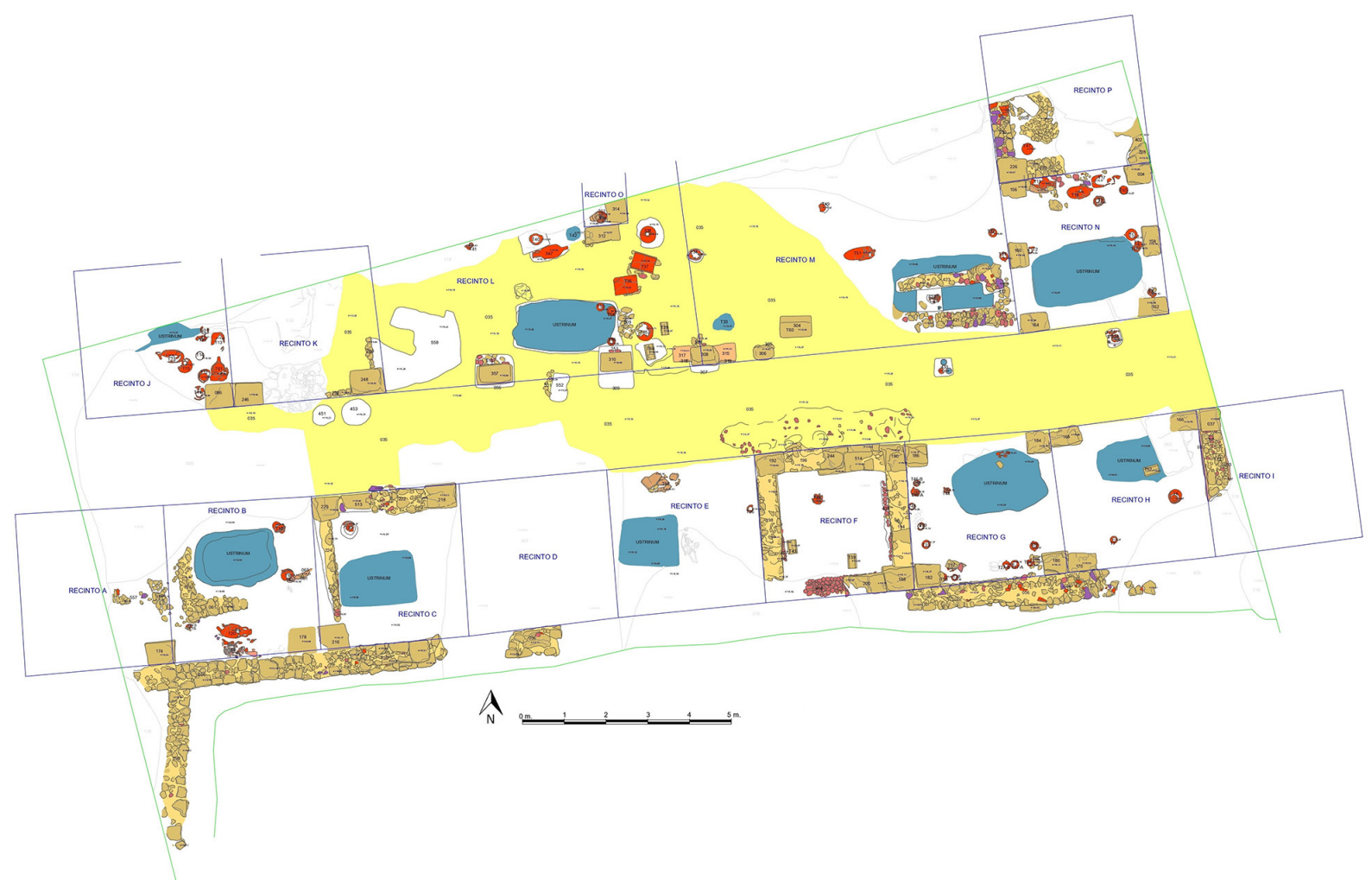

Fig. 2. Planta general del sepulcretum, con señalización de los diferentes recintos funerarios distinguidos en la intervención.

50 cremaciones $^{12}, 2$ posibles cremaciones, 11 inhumaciones perinatales y 2 posibles inhumaciones también perinatales. En una de las posibles cremaciones solo se localizó el supuesto ajuar que acompañaba al enterramiento; en la otra la urna aparecía dañada por una deposición posterior y no se documentaron restos óseos humanos en su interior. Las dos posibles inhumaciones se correspondían con ánforas cortadas longitudinalmente sin restos humanos, quizás porque se descompusieron sin dejar rastro. En total han podido ser identificados, provisionalmente, 63 individuos: 52 cremados y 11 inhumados.

La batería de recintos meridional quedaba delimitada en su parte trasera por un muro de $0,70 \mathrm{~m}$ de ancho y una potencia conservada en algunos puntos de $1,31 \mathrm{~m}$, construido en mampostería combinada con algo de sillería, que no sirvió de cierre a los recintos,

12 Dos de ellas son dobles. El estudio antropológico de los restos está siendo realizado por E. García-Prosper y M. Polo, del Laboratorio Paleolab de Valencia. por cuanto estos apoyaron su fachada trasera en él. Así se observa con toda claridad en el Recinto G. Ello no evitó que en algunos casos los enterramientos buscaran su 'protección'. Tal circunstancia parece abogar por un sector funerario con entidad propia: promotores privados o públicos pudieron haber comprado un terreno, o derivado en este mismo sentido un espacio privado o público -sin perder de vista que, como en Sarsina o Tolentinum, pudiera haber sido donado-, para después compartimentarlo y venderlo con fines cementeriales y carácter especulativo, dada la altísima demanda que debió existir de suelo funerario en Colonia Patricia desde principios del Imperio, máxime en una zona tan cercana a las murallas y a vías de especial importancia en los primeros siglos de ocupación romana ${ }^{13}$. Con todo, el carácter

13 El sepulcretum de la avda. de las Ollerías, ya aludido más arriba, parece responder a una dinámica y cronología inicial similares y, sin embargo, se encuentra a una milla larga de la puerta septentrional de la urbe, por lo que incluso argumentos en apariencia tan obvios deben ser tomados con cautela. 
marcadamente modular, racionalista y funcional de la topografía inicial del sepulcretum no se mantuvo en el tiempo, y tras una primera línea de recintos bastante uniformes, la segunda y la tercera observarán dinámicas algo diferentes que la casuística arqueológica no ha permitido determinar en sus últimos detalles $-c f$. infra-.

En el relleno de la zanja de cimentación del citado muro trasero se recuperó una lucerna muy fragmentada pero prácticamente completa del tipo Loeschcke III, con decoración geométrica en el disco, dos piqueras y asa plástica, cuya producción comienza en época augustea, aunque alcanza su mayor auge en la primera mitad del s. I d. C. (Morillo, 2015: 354-455); cronología que en principio predomina en la necrópolis, si bien algunos indicios parecen apuntar hacia el cambio de Era como fecha de arranque para la misma. Finalmente, en la cara meridional de su extremo occidental se le adosaba una segunda estructura construida en mampostería y con dirección $\mathrm{N}-\mathrm{S}$, perpendicular, por tanto, a aquel, que quedaba embutido en el perfil o. Quizás el espacio funerario se prolongó también por ese lado; sin embargo, no se recuperó en él enterramiento alguno ni ningún otro vestigio arqueológico, a pesar de la amplitud del área intervenida. Fue, pues, en apariencia, un área baldía -tal vez hortus, jardín funerario o espacio de reservade difícil interpretación por el momento.

La mayor parte de los recintos documentados -A, B, C, F, G, H, I, J, K y P- estaban delimitados por cipos de calcarenita -no todos conservados-, dispuestos verticalmente en cada una de sus cuatro esquinas, y eran de planta cuadrangular, con una superficie uniforme de 3,55 m por 3,55 m -12 x 12 pies romanos-. Por si había alguna duda, los Recintos F y G conservaban en su parte trasera sendos

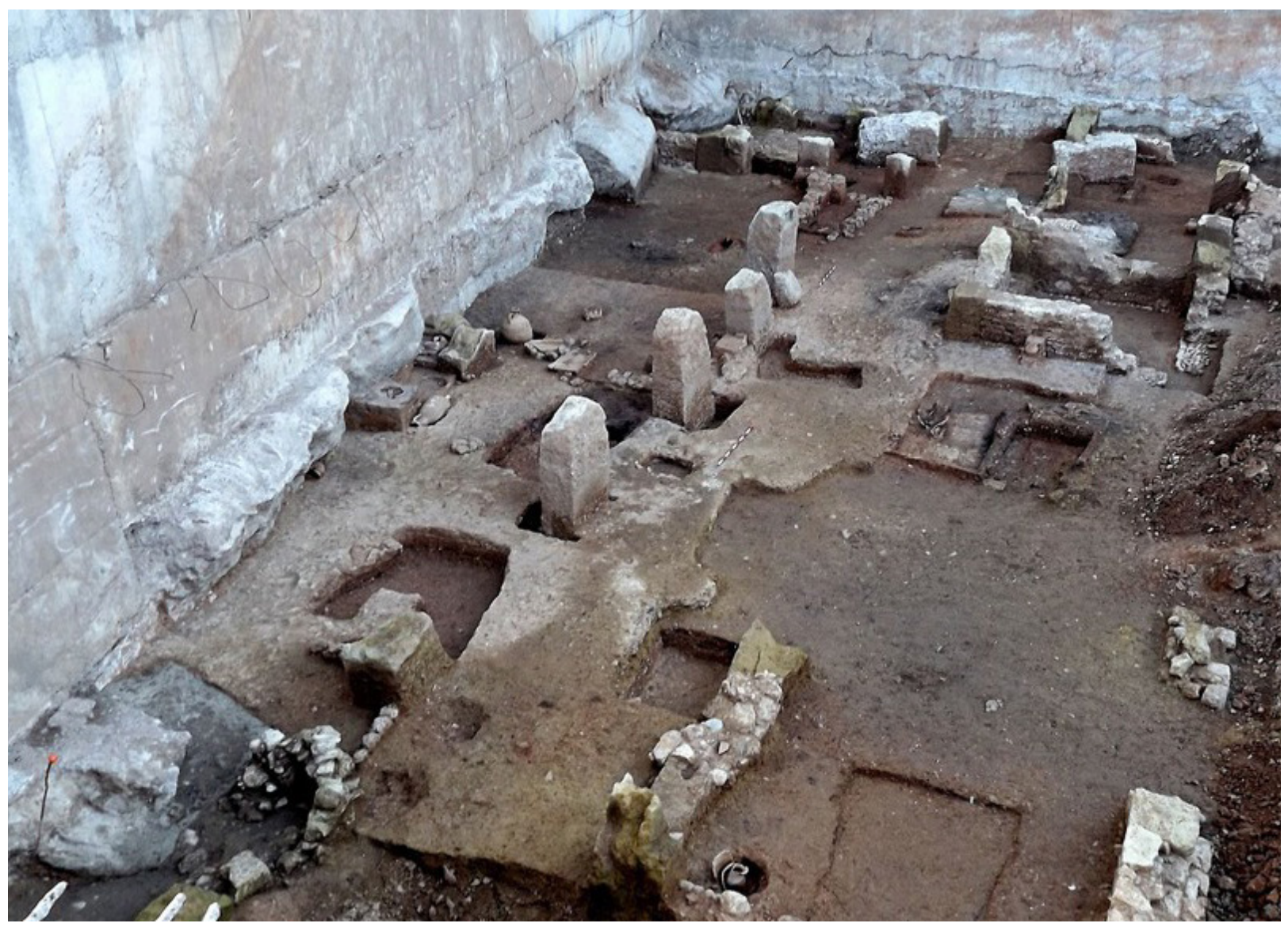

FIG. 3. Panorámica del sepulcretum vista desde el o. 
cipos de cabecera redondeada -el tipo predominante en el sepulcretum $-{ }^{14}$ con el epígrafe en su cara frontal L(ocus) $P$ (edum) XII, indicatio que corrobora la realidad arqueológica y alude al módulo mayoritario en Llanos del Pretorio y en Córdoba ${ }^{15}$. El del Recinto F quedó, además, embutido en el ángulo de sus muros de cierre oriental y meridional. Ambas circunstancias parecen indicar que, una vez repartidos y ocupados los diferentes lotes de tierra, la función principal de las mensurae sepulcri ${ }^{16}$ quedaba asumida en gran medida por la propia materialidad de los termini o de la construcción.

Al igual que se observa, por ejemplo, en algunos recintos de la avda. de las Ollerías (Ruiz Osuna, 2007: 34 y ss.; Vaquerizo y Sánchez, 2008: 124 y ss. $)^{17}$, la delimitación entre acotados contiguos en Llanos del Pretorio se hizo -con la única excepción de L y M, que comparten terminus; vid. infra- mediante cipos gemelos, dos a dos, uno por recinto, dos en fachada $y$, a veces, dos en las traseras, más dos en los laterales en el caso del N. En el Recinto B solo se constató el de su ángulo SE. Los dos de su fachada $\mathrm{N}$ quizás fueron arrasados por la fosa contemporánea que afectó a este sector, pero el de la esquina so podría no haber existido, lo que complicaría la casuística incidiendo en la idea de que cada lote funcionó conforme a una dinámica propia. Si tenemos en cuenta, por otra parte, que durante el proceso de excavación no se detectó huella arqueológica alguna de los posibles sistemas de cierre de aquellos acotados que no fueron delimitados por muros de mampostería-balaustradas, vallas de madera, vegetación,

14 Utilizamos el término cipo frente al de estela por el grosor de las piezas, casi igual al de su frente, lo que les da una sección de ligera tendencia rectangular en la mayor parte de los casos.

15 Estos dos ejemplares vienen a sumarse a los otros 10 termini con mensurae sepulcri ya conocidos en la ciudad. En ellos, el módulo de 12 x 12 pies representa el 80\% (Vaquerizo y Sánchez, 2008: 104; 2009).

16 Debió, probablemente, ser opción personal del adquiriente a la hora de seńalizar su compra hacerlas grabar sobre piedra; modalidad que quizás implicó mayor precio. En cualquier caso no debemos descartar otras formas de señalización, entre las cuales los tituli picti debieron ocupar un lugar de preferencia.

17 Cf. López Jiménez, op. cit. n. 3. cuerdas, etc.-, debemos suponer en principio que los cipos de las esquinas y ocasionalmente los lados bastaron para señalizar los respectivos loci ${ }^{18}$.

Hubo, de hecho, excepciones, que a la manera de otros muchos ejemplos repartidos por las diversas áreas funerarias patricienses cerraron los loci mediante muros de fábrica monumentalizando sus entradas ${ }^{19}$; algo que, más allá de ser una simple opción personal o familiar, dejaba, por un lado, constancia de mayor poder adquisitivo y, por otro, singularizaba las tumbas, al tiempo que las protegía. Así ocurrió con los Recintos C, F, $\mathrm{I}^{20}$ y K, y quizás L, M y p, si bien solo nos ha llegado completo el segundo de ellos -Recinto F - Se tapió mediante muros de mampostería en sus cuatro lados, con una entrada en fachada flanqueada por dos cipos de calcarenita -uno de ellos marcaba el ángulo nororiental del acotado-, escalón de acceso al interior, de nivel más bajo que la calle, y un cuidado remate en el revestimiento interior de los muros mediante incisiones en el mortero que intentaron imitar un despiece de sillería. Tanto este escalón como el que daba entrada al Recinto C -ambos de piedra local-contaban con sendas quicialeras, prueba irrefutable de la existencia de una puerta, en principio de madera ${ }^{21}$.

Parecen romper la dinámica general los Recintos E, L, M y O, cuya organización, en principio,

18 Existen grandes posibilidades de que muchos de los acotados funerarios documentados en la ciudad fueran señalizados simplemente mediante material perecedero. De ser así, se nos dibujaría una topografía funeraria mucho más compleja y sistematizada de la que hasta ahora hemos logrado perfilar.

19 Que no siempre existieron. Fue bastante común que los recintos presentaran sus muros ciegos, incluso cuando alcanzaban alturas superiores a las de un hombre medio. Esto obligaba a saltarlos cada vez que se debía realizar algún enterramiento en su interior.

20 Del Recinto I solo se pudo documentar su cipo noroccidental y parte del muro de mampostería - de un grosor considerable y con revestimiento de mortero de cal- que lo cerraba por el o, aun cuando cabe deducir que siguiera el módulo de 12 x 12 pies imperante en toda esa línea de acotados. El resto del espacio funerario se introduce en el perfil E. No proporcionó ningún enterramiento.

${ }_{21}$ Recintos con escalones y quicialeras en las entradas fueron observados también en el estudio de la via Corduba-Hispalis realizado por uno de nosotros (Ruiz Osuna, 2005). 
no sigue el módulo mayoritario. En el caso del Recinto $\mathrm{E}$, dos fosas de épocas califal y contemporánea deformaron por completo su aspecto original. Tal es así que no conserva ninguno de sus cipos delimitadores -si es que existieron $-^{22}$. Con todo, la distancia entre el Recinto C y el F es exactamente de 7,10 m, es decir, el tamaño que ocuparían dos acotados de 12 x 12 pies de tamaño; de ahí que hayamos supuesto la existencia entre ellos de dos recintos más, D y E, aun cuando como es lógico no cabe descartar

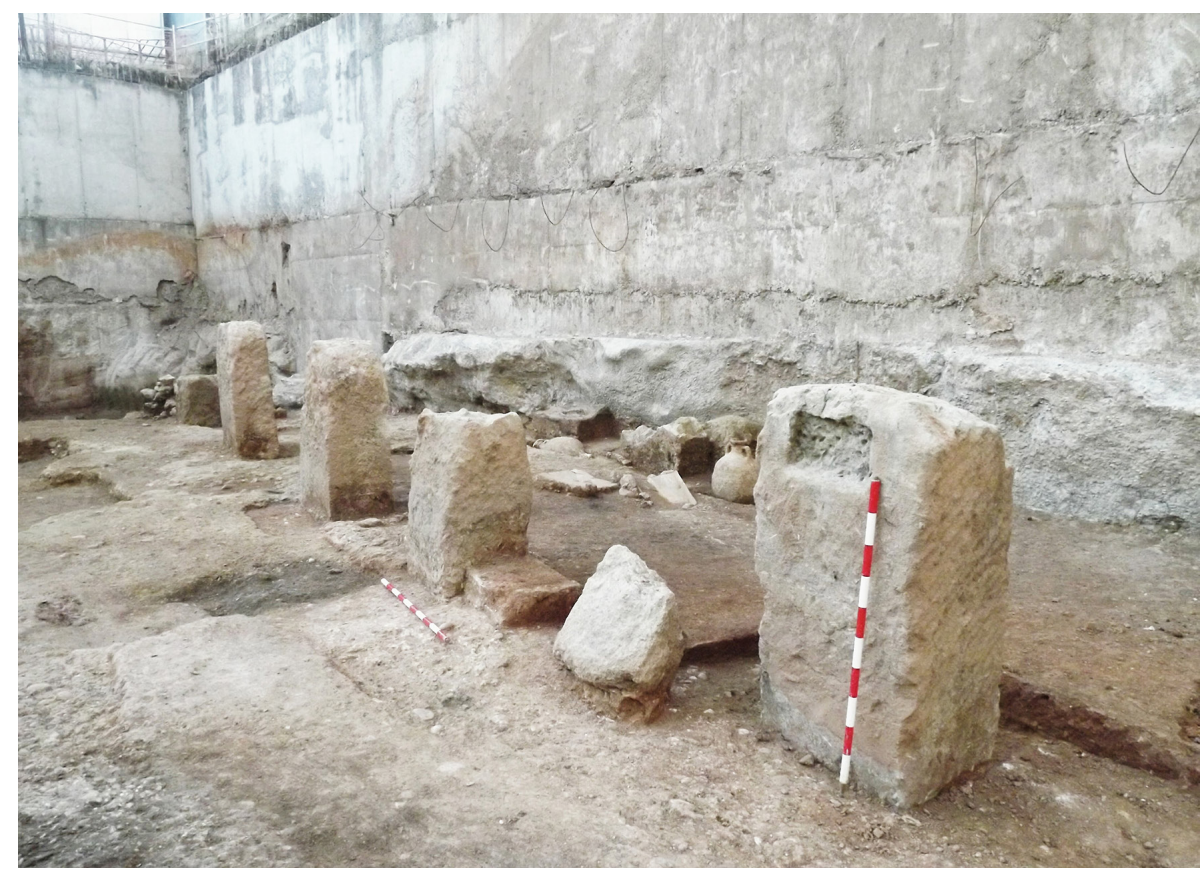

FIG. 4. Fachada de los Recintos Funerarios L y M, conformada por cipos con remate semicircular. que un mismo propietario pudiera haber adquirido dos lotes.

Más complicado es el caso de los Recintos L y $\mathrm{M}$, que según todos los indicios fueron concebidos conforme a un esquema diferente: en lugar de los bloques de ángulo habituales en el resto de los casos presentan una fachada salpicada por cipos de cabecera redondeada unidos por muros de tapial (Fig. 4) que incluso han conservado parte de su revestimiento original, y podrían haber quedado separados por un muro de mampostería que, con apenas una hila$\mathrm{da}$, fue documentado en su arranque junto al cipo que ambos comparten. Aun cuando con una potencia mucho menor, el pavimento de picadura de sillar utilizado en la vía funeraria se prolonga en el espacio ocupado por ellos, roto por las zanjas de cimentación de los bloques de fachada, así como por las fosas de algunos de los enterramientos y de uno

22 Por el momento resulta imposible determinar si los cipos delimitadores eran dispuestos a voluntad por los compradores o bien de oficio por parte del propietario del terreno, autor de su división en lotes y promotor de las ventas. Este tipo de excepciones parecen abogar de nuevo por la primera de las opciones.

de los ustrina. Tal circunstancia sugiere que pudiera haberse tratado inicialmente de un espacio abierto o de tránsito hacia la segunda vía situada más al $\mathrm{N}$ -que pudo ser posterior-, o quizás incluso de reserva, después estructurado en dos acotados de 12 x 12 pies (Recintos $\mathrm{J} \mathrm{y} \mathrm{K}{ }^{23}$ y dos más (Recintos L y M) de dimensiones bastante inusuales pero idénticas in fronte $\left(51,75\right.$ pies) e in agro (12 pies) ${ }^{24}$. Quien dividió en lotes el terreno pudo haber dejado esta zona sin compartimentar por razones hoy imposibles de determinar, o bien alguien compró uno o varios lotes de dimensiones mayores que el resto. De cualquier forma, sorprende sobremanera la ruptura del ritmo modular tan marcado y uniforme del resto de acotados -dispuestos como ya hemos señalado

23 En el Recinto J no se documentó el pavimento de picadura de sillar. Sí, en cambio, en el Recinto $\mathrm{K}$, donde se entrega a los cipos. Todo ello es indicativo de las dificultades existentes para interpretar convenientemente la secuencia estratigráfica en este punto del sepulcretum.

24 Espacios abiertos intermedios de este mismo tipo han sido detectados en otros sepulcreta de la ciudad, caso de La Constancia (Vaquerizo et al., 2005: 66), y en otros lugares del Imperio como Ostia o Isola Sacra (Calza, 1940; Heinzelmann, 2000; Taglietti, 2001; Baldasarre, 2002). 
en batería-, y que por otra parte la suma de los pies de fachada de los Recintos L y m no sea múltiplo de 12. Su dinámica particular de momento se nos escapa. Son el mejor ejemplo de que este tipo de necrópolis eran espacios vivos, en permanente conformación y transformación.

También el supuesto Recinto o rompe por completo con la modulación de la que podría haber sido la tercera línea de acotados funerarios, contigua en teoría a la segunda por sus medianeras traseras, tal como se comprueba en la disposición del Recinto P. Confirma así que en este sector central del sepulcretum las cosas funcionaron de manera diversa, por razones que con la información disponible no podemos concretar. El único cipo conservado del Recinto o corresponde probablemente a su esquina $\mathrm{SE}^{25}$, cuya protección buscan de nuevo los enterramientos. El sillar con el que forma ángulo hacia el oeste se dispone dentro del área del Recinto L, que podría haber cerrado su parte trasera con una batería de cipos similar a los de fachada.

\section{Recintos y enterramientos}

\subsection{Recinto $B^{26}$}

Delimitado, a su espalda, por el muro que cierra el sepulcretum en su frente $s$, da fachada a la vía inserto en la serie de recintos meridional, todos de $12 \times 12$ pies, pero solo ha conservado un cipo en su ángulo $\mathrm{SE}$, sin que sea posible determinar si fue el único o ha perdido el resto.

25 Dadas las circunstancias anteriores, no descartamos otras opciones, como que los cipos se dispusieran en línea, o incluso sin un criterio estricto. El Recinto L es el mejor ejemplo al respecto.

26 En el inventario que sigue hemos obviado los Recintos A, D, I y K. El primero quedaba embutido en el perfil o de la excavación y solo se documentó parte de su lateral oriental. Del Recinto I, que hacía lo propio en el perfil E, solo constatamos parte de su lateral occidental. El posible Recinto D había desaparecido víctima de una gran fosa de cronología contemporánea. Y, por fin, el Recinto k quedaba embutido en el perfil $\mathrm{N}$ y su interior se vio afectado por construcciones contemporáneas.
Proporcionó seis enterramientos: cinco cremaciones secundarias en urna cerámica -Enterramientos 8, 9, 10, 16 y 67; este último solo posible, ya que fue dañado por el Enterramiento 9, en un claro ejemplo de superposición- y una inhumación infantil en ánfora cortada longitudinalmente. La olla ossuaria del Enterramiento 8 fue depositada sobre el cadáver de un perro de gran tamaño y avanzada $\operatorname{edad}^{27}$, tal vez sacrificado a la muerte de su dueño/a (Fig. 5). También apareció malacofauna afectada por la acción del fuego, posible resto de un banquete funerario desarrollado durante la cremación del difunto o parte de su propio ajuar con cierto carácter profiláctico, tal como ha sido señalado recientemente en Baelo Claudia (Prados, 2017: 78, fig. 3).

En la zona central del recinto fue documentado un ustrinum delimitado al $s$ y al o por sendos muros de mampostería, el primero de ellos con restos de su revestimiento original a base de mortero de cal. En él pudieron identificarse las huellas de al menos cuatro cremaciones separadas por capas de cal o de $\operatorname{arcilla}^{28}$. Entre las cenizas de cada una de ellas recuperamos varios ungüentarios de cerámica fechados entre finales del s. I a. C. y la primera mitad del s. I d. C. (Py, 1993).

\subsection{Recinto $C$}

Junto con los Recintos F, I, $\mathrm{K}^{29}$ y P -quizás también el A-, es uno de los pocos que cerraron el locus, de 12 x 12 pies, con muros de mampostería, si bien solo nos han llegado restos de ellos en sus laterales

27 La arqueofauna recuperada durante la excavación está siendo objeto de estudio monográfico a cargo de R. Martínez Sánchez, de la Univ. de Granada.

28 El estudio de sedimentos, así como de los restos antracológicos y carpológicos recuperados durante la excavación corre a cargo de L. J. Sánchez Hernando.

29 Los laterales s y o del Recinto $\mathrm{K}$ estaban cerrados por sendos muretes de mampostería, pero su función parecía más relacionada con marcar los límites del acotado que con impedir el acceso al mismo. Debió contar también con una superficie de 12 × 12 pies, aunque solo conservaba los cipos de fachada. No proporcionó enterramientos, seguramente afectados por un pozo negro de época califal y la construcción del muro pantalla del edificio de viviendas actual. 
$\mathrm{N}$ y o, de bastante mejor factura el primero y mucho más endeble el segundo por razones que no alcanzamos a preci$\operatorname{sar}^{30}$. Debió contar en sus cuatro ángulos con los consabidos cipos pétreos, arrasado el de la esquina SE por una fosa posterior que posiblemente destruyó también las paredes de esa zona, si es que existieron. Contó en su fachada $\mathrm{N}$ con una entrada que, como en el caso del Recinto $\mathrm{F}$, bajaba al interior del acotado mediante un escalón de calcarenita con quicialera; y en su parte central dispuso de un

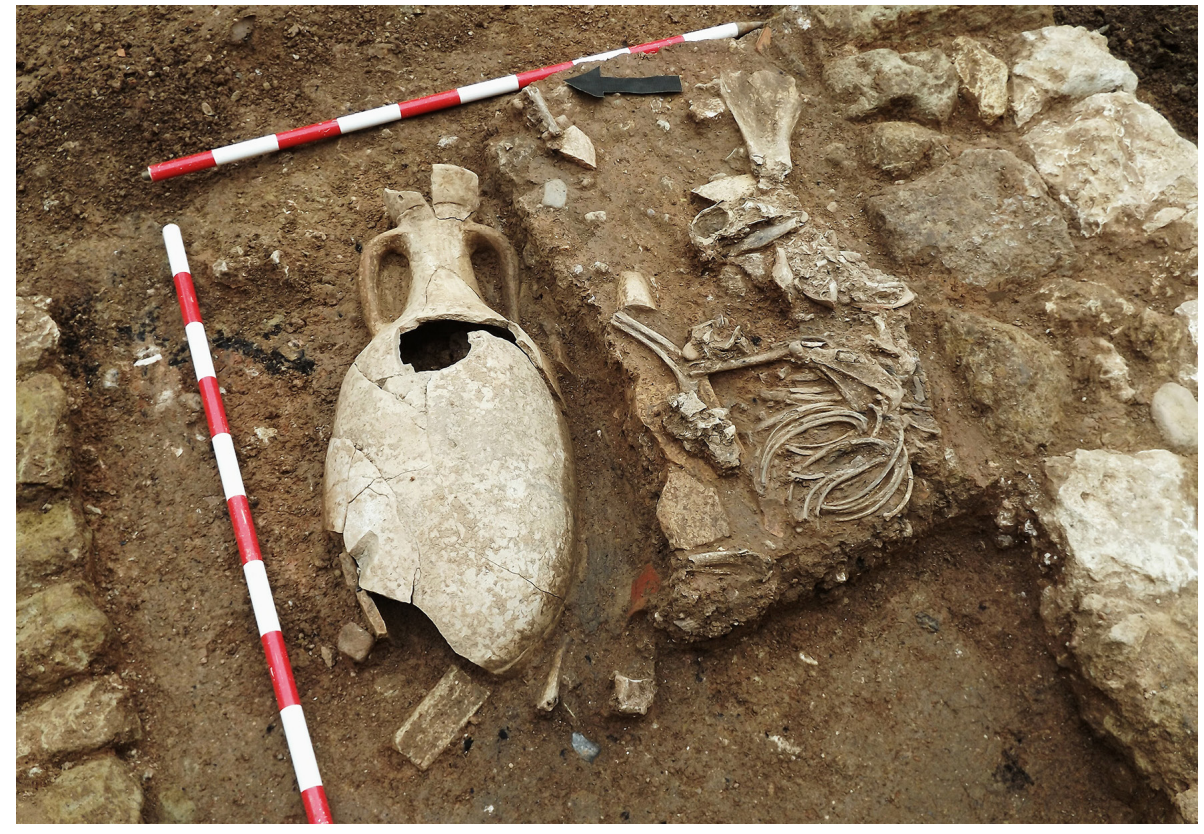

Fig. 5. Recinto C: detalle del cánido documentado, en el Enterramiento 8, junto al Enterramiento 20. ustrinum en el que se realizó una sola cremación, presumiblemente identificable con el único enterramiento localizado (n. ${ }^{\circ} 30$ ), de carácter secundario, en urna cerámica protegida por un gran fragmento de ánfora y sin ajuar.

\subsection{Recinto $E$}

Se trata de uno de los espacios del sepulcretum más problemáticos, por cuanto no ha conservado elemento alguno de delimitación, salvo el muro occidental del Recinto F, que le sirve de medianera por el este, y la vía funeraria a la que abre, por el $\mathrm{N}$. En este tramo no se conserva el muro que enmarca el sector funerario por el s, ni tampoco cuenta por el oeste con ningún otro acotado definido hasta alcanzar el Recinto c, circunstancia que obedece en buena medida a las afecciones provocadas en la zona por las acciones estratigráficas de momentos

30 Si superponemos a nuestra planimetría la elaborada en su momento por R. Penco, primera arqueóloga que actuó en el solar, en el lugar que ocupa este muro ella documentó uno de tapial, por lo que podría tratarse de su cimentación. posteriores $^{31}$. Aun así, supuestos los dos límites conservados, la propia dinámica de la batería meridional de recintos, y el hecho de que el espacio vacío en sentido E-O equivalga exactamente a 24 pies, nos ha llevado a distinguir en él dos acotados de 12 x 12: el Recinto D, que sí conserva por su lado meridional un fragmento del muro general de cierre y no proporcionó información funeraria alguna; y el Recinto $\mathrm{E}$, en el que fueron localizadas una cremación secundaria en urna cerámica -Enterramiento 26- y una inhumación en ánfora cortada longitudinalmente y protegida mediante fragmentos reaprovechados de opus signinum que la cubrían por completo -Enterramiento 50-, en una fórmula que solo tiene parangón con la empleada en el Enterramiento 17 del Recinto $\mathrm{N}$; si bien en este caso el opus signinum fue vertido sobre el ánfora. La cremación incluía un ungüentario de vidrio en el interior de la olla ossuaria ${ }^{32}$.

31 No hay que descartar en cualquier caso la posibilidad de que el recinto no hubiera dispuesto en ningún momento de cipos delimitadores.

32 La sistematización del material vítreo corre a cargo de un equipo formado por A. Velo (Univ. de Granada), Ch. E. Durkworth (New Castle Univ.) y D. J. Govantes-Edward (Univ. de Córdoba-Univ. Nova de Lisboa). 
En la parte central del recinto se constataron restos de varios ustrina muy afectados por sendas fosas de épocas califal y contemporánea que de manera excepcional se superponían, cortando las fosas de los más recientes a los más antiguos. Todos tenían huellas de rubefacción, pero aparecieron rellenos de arcilla, sin cenizas ni restos quemados, retirados minuciosamente tras cada una de las cremaciones.

\subsection{Recinto $F$}

De 12 x 12 pies de lado, cerró el espacio entre los habituales cipos delimitadores con muros de mampostería cimentados sobre cantos de río trabados con barro (Fig. 6). En su fachada a la vía se dotó de entrada mediante la incorporación de un quinto cipo central que la flanqueaba junto con el de la esquina nororiental, y que permitía bajar al interior mediante un escalón de calcarenita con quicialera. La cara interna de los muros - con excepción del $\mathrm{N}-$ fue revestida con mortero de cal decorado con incisiones que pretendían imitar un despiece de sillería. La esquina so del edificio, así como el cipo que lo delimitaba por este lado, se vieron afectados de forma traumática por una fosa posterior y han desaparecido. Finalmente, el cipo del ángulo SE presentaba en su cara interior el titulus $L$ (ocus) P(edum) XII, si bien la inscripción no quedaba a la vista tras quedar embutido el soporte en el ángulo entre ambos muros. El acotado proporcionó tres cremaciones secundarias en fosa simple: el

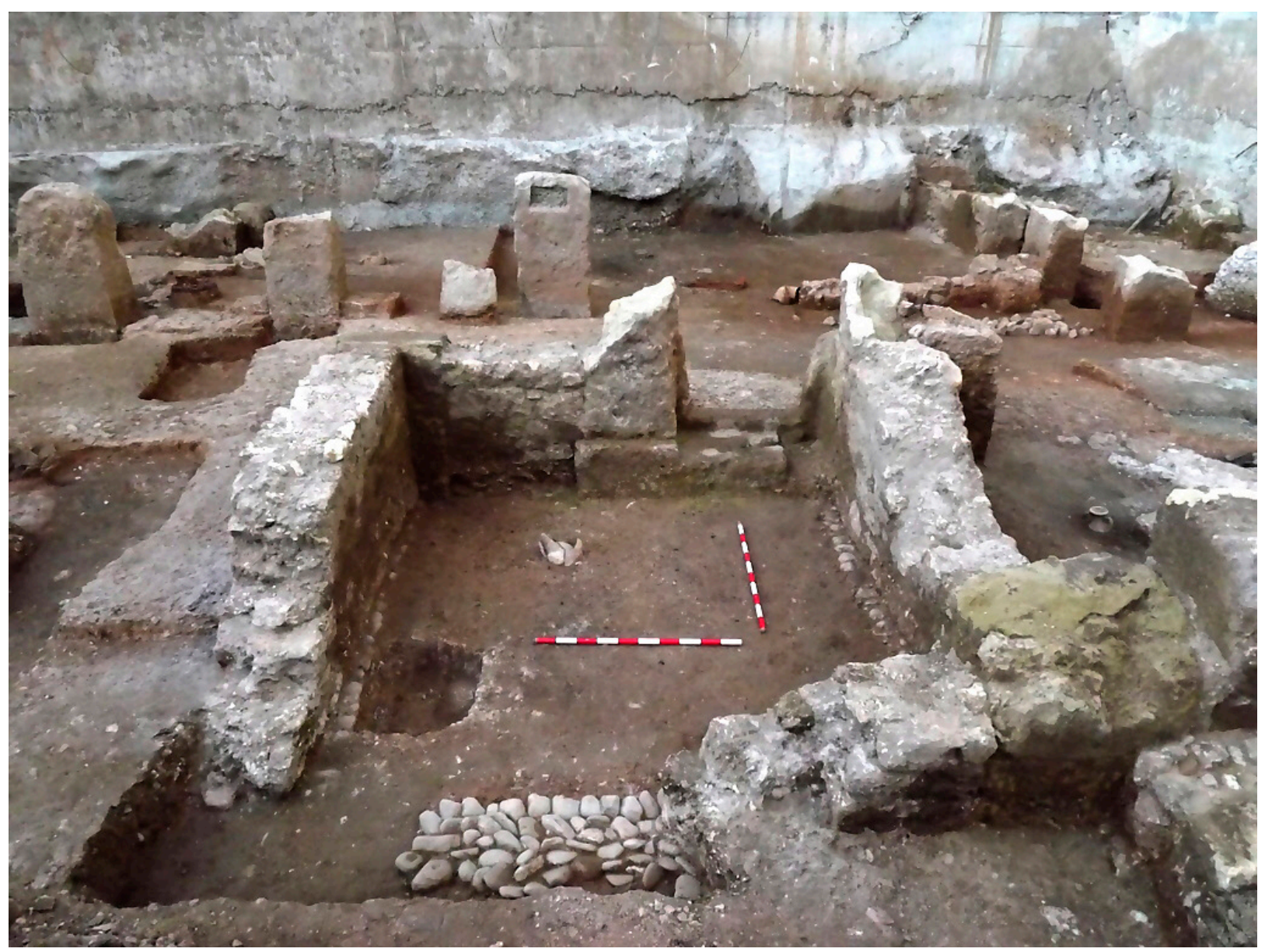

Fig. 6. Recinto Funerario F visto desde el s; en primer término, cimentación de los muros que cierran sus laterales, a base de cantos rodados trabados con barro. 


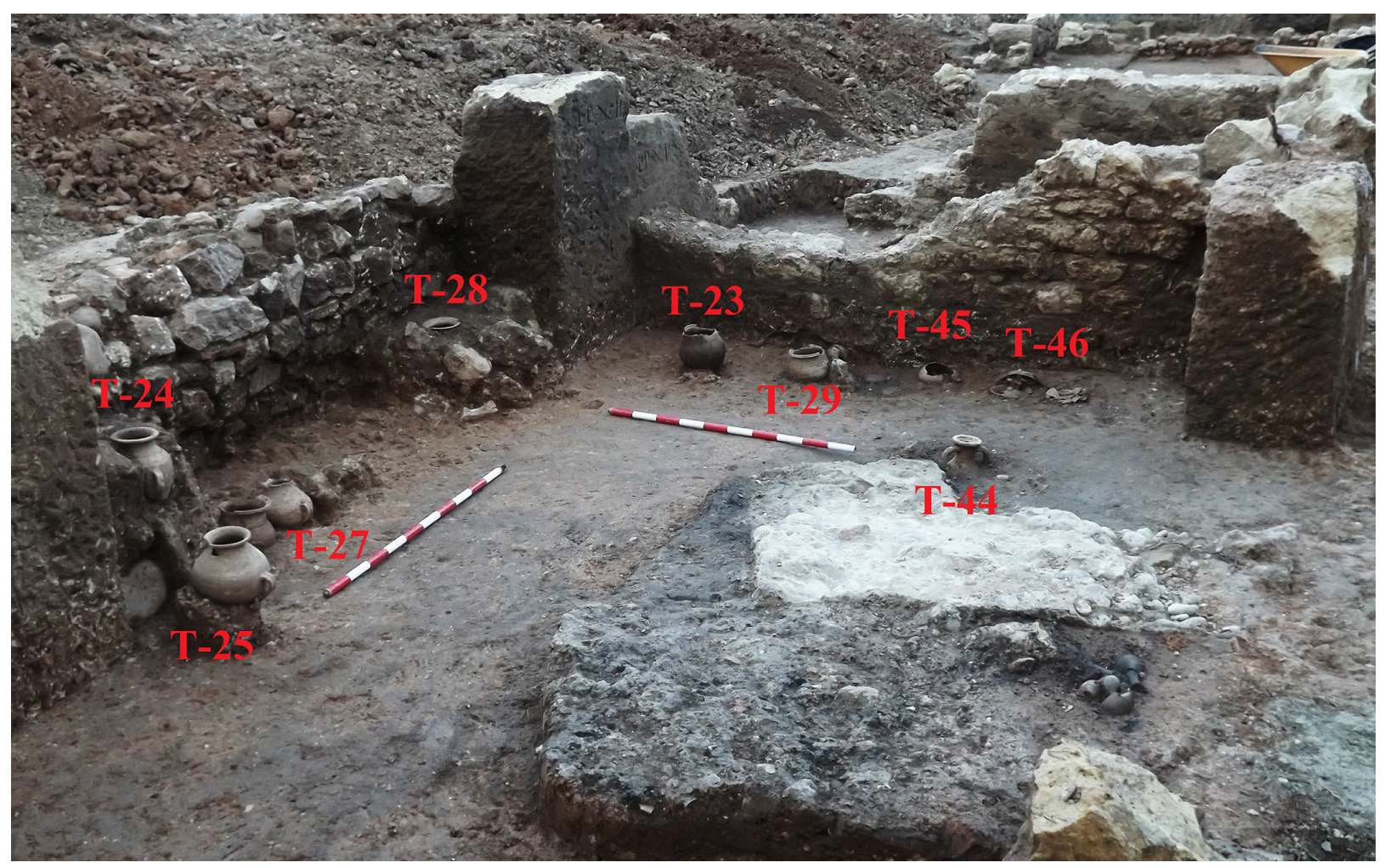

Fig. 7. Disposición de los enterramientos en el Recinto Funerario G.

Enterramiento 48, en urna cerámica protegida por un gran fragmento de ánfora, sin ajuar, y los Enterramientos 43 y 59 , en ollae ossuariae de piedra que incorporaron en su interior, junto a los restos óseos, sendos ungüentarios de vidrio.

El Recinto F es uno de los pocos del sepulcretum que no contaba con ustrinum -0 , por lo menos, no fue posible individualizarlo-. Con todo, el hecho de que entre sus niveles de colmatación aparecieran numerosas cenizas y que el cipo con indicatio pedaturae presentara signos de rubefacción en su parte derecha nos lleva a plantear que ocasionalmente pudiera haberse dispuesto alguna pira en su parte central. En aquel mismo estrato de colmatación fueron recuperadas dos tabellae defixionum de plomo, objeto reciente de un estudio específico (García-Dils y Rubio, 2018).

\subsection{Recinto $G$}

Estaba delimitado por cuatro cipos, uno de los cuales -el de su esquina so- incluía de nuevo en su cara frontal, dando, pues, vista al interior del espacio funerario, el titulus $L$ (ocus) $P$ (edum) XII, $12 \mathrm{x}$ 12 pies -unos 144 pies cuadrados-, que se corresponden a la perfección con la realidad arqueológica documentada ${ }^{33}$. Por la cara posterior los cipos se adosaban al muro que delimitaba el sepulcretum por el lado meridional, corroborando su posterioridad.

En el Recinto G pudimos excavar 12 enterramientos $-23,24,25,28,29,44,45,56,57$ y $58-^{34}$, dos de ellos dobles -27 A-B, y 46 A-B-, lo que no implica necesariamente que se trate de dos individuos. En todos los casos hablamos de cremaciones en ollae ossuariae cerámicas -con excepción de una vitrea-, depositadas en fosas simples y calzadas en su mayoría mediante acumulación de mampuestos y/o fragmentos de ánforas. Salvo en el caso del

33 Así pudo comprobarse también en la avda. de las Ollerías (Ruiz Osuna, 2007).

34 La apertura de alguna de las fosas - caso de los Enterramientos 24 y 28 - afectó a deposiciones previas -Enterramientos 56 y 57 , respectivamente-. 
Enterramiento 44 buscan expresamente la protección de los muros meridional y occidental (Fig. 7). Esta circunstancia obedece a una finalidad más práctica que simbólica: dejar espacio para la disposición del ustrinum, que conservaba restos de, al menos, dos cremaciones separadas entre sí por una capa de arcilla. Lamentablemente, apenas pudo ser excavada una parte mínima del mismo, al haber sido afectado por las cimentaciones de hormigón de época contemporánea.

En este acotado se hace casi normativa la presencia como único ajuar de un ungüentario de vidrio en el interior de la olla ossuaria o a los pies de la misma. Tal ocurre en los Enterramientos 2335, 27-в, $28,29,44,45,46 \mathrm{~A}^{36}, 56$ y 58. Destaca entre todos ellos el Enterramiento 44, una cremación secundaria en urna de vidrio de forma ovoide, gran tamaño, base cóncava y borde ancho, protegida con un ánfora del tipo Dressel 20a/Oberaden 83/Ovoide 6 de finales del s. I a. C.-primer cuarto del s. I d. C., cuya boca aparecía taponada con un fragmento de cerámica común, por lo que no cabe descartar que fuera utilizada además como tubo de libaciones ${ }^{37}$.

\subsection{Recinto $H$}

Con una superficie de $12 \times 12$ pies, debió estar delimitado por cuatro cipos -el de la esquina sE fue arrasado por una fosa de época contemporánea- y, a su espalda, por el muro que cierra la necrópolis en su lado meridional. Alojaba solo tres tumbas de cremación en urna, dos cerámicas -Enterramientos 6 y $7-$ y la tercera una caja de piedra -Enterramiento 52-. Esta última fue amortizada por el ustrinum

35 Este incluía además una varilla de bronce, muy fragmentada, usada tal vez como removedor de ungüentos o perfumes.

36 En el Enterramiento 46A se añadió a los restos óseos una cajita metálica que posiblemente contuvo algún tipo de amuleto no conservado-¿cabellos; dientes de leche...?-.

37 En Córdoba lo normal es que las urnas de vidrio aparezcan protegidas por fundas de plomo. No obstante, en el Enterramiento 20 del vecino sepulcretum de La Constancia, tanto la urna de vidrio como su funda de plomo fueron cubiertas también con el cuerpo de un ánfora, en este caso sin cuello, asas ni fondo (Vaquerizo et al., 2005: 101-102).
(Fig. 8), una fosa de bordes rubefactados construida encima aunque sin afectar a la deposición previa, en un claro ejercicio de superposición estratigráfica que indica cierto margen temporal. Conservaba en su interior los restos de una cremación, en esencia ceniza sin ningún tipo de material asociado. Solo el Enterramiento 7 incluía como ajuar una moneda ${ }^{38}$. No obstante, en el nivel de colmatación de este recinto fue recuperada una tercera tabella plumbea de carácter mágico (García-Dils y Rubio, 2018).

\subsection{Recinto J}

Inaugura por el extremo occidental la segunda línea de recintos, que abren a la vía principal por su fachada s, pero no pudo ser documentado en su totalidad por introducirse en el perfil $\mathrm{N}$ y haberse visto afectado por la misma fosa que destrozó el Recinto B, derivada del primer Seguimiento Arqueológico. Con todo, aun cuando solo ha conservado el cipo $\mathrm{SE}$, cabe presumir que fuera de $12 \times 12$ pies. Proporcionó nueve enterramientos, seis cremaciones secundarias en urna cerámica (Enterramientos 11, 12, 14, 15, 21 y 63), dos inhumaciones infantiles en ánforas cortadas longitudinalmente (Enterramientos 13 y 22) y una posible inhumación infantil (Enterramiento 61). La tumba 21 se superpuso a la 63, danándola. Ninguna de las inhumaciones presentaba ajuar. Tampoco las cremaciones, con excepción del Enterramiento 12, que incorporaba un ungüentario de vidrio junto a la urna, en el interior de la cista. Varias fueron calzadas con grandes fragmentos de galbos de ánforas.

En la parte central del recinto se documentaron restos de un ustrinum con cimentación a base de mampuestos de calcarenita. Conservaba los restos de hasta tres cremaciones, separadas por capas de cal o de arcilla. Su localización, junto al perfil N, y la construcción del correspondiente muro pantalla impidieron la recuperación de cualquier tipo de material en el escaso espacio conservado.

38 El numerario recuperado en el sepulcretum está siendo estudiado por A. Arévalo y E. Moreno, de la Univ. de Cádiz; sobre el papel de la moneda en ámbito funerario, $c f$. Arévalo, 2016. 


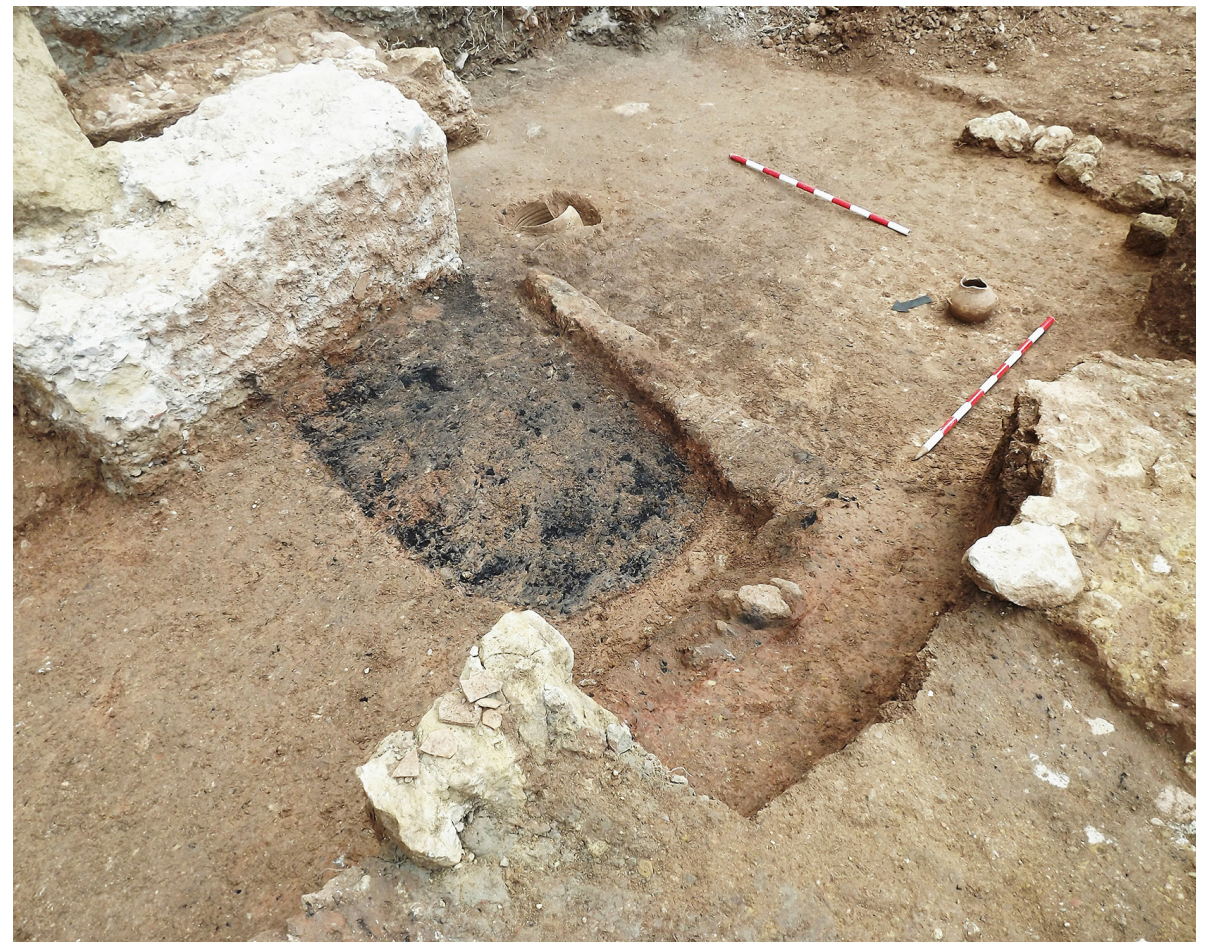

FIG. 8. Recinto Funerario H (vista desde el NE), con su correspondiente ustrinum en primer término.

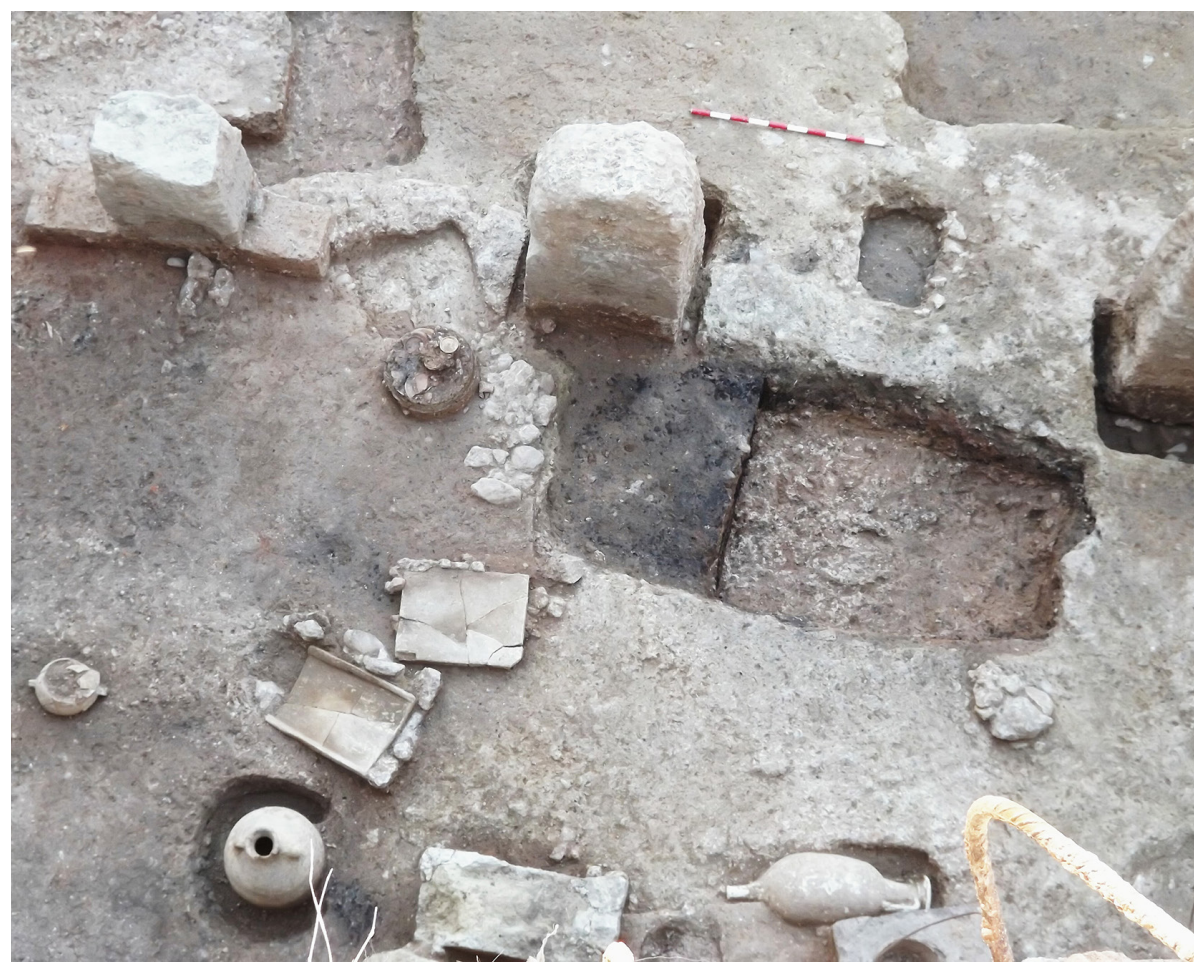

FIG. 9. Vista cenital del Recinto Funerario L.

\subsection{Recinto L}

Es uno de más problemáticos y complejos del sepulcretum (Fig. 9), dado que, por un lado, parece algo más tardío que el resto en cuanto a su trazado $^{39}$; por otro, disponía solo del cipo de esquina SE, que habría compartido con el Recinto M, separados por un pequeño muro de mampostería; y finalmente sus fachadas ${ }^{40}$ se organizaban a través de cipos de calcarenita de cara exterior desbastada, cimentación de cantos rodados trabados con barro y remates semicirculares, que pudieron quizás acoger tituli picti hoy perdidos. Quedarían unidos mediante muros de tapial de los que se documentaron dos pequeños tramos junto al cipo separador entre ambos acotados, con una finalidad aparentemente más relacionada con marcar los límites de

39 Habría ocupado parte de aquel primer espacio libre pavimentado con picadura de sillar, como la vía a la que abre por su fachada s, y en principio prolongación de ella.

40 Con seguridad, la s, que abría directamente a la vía, pero quizás también la $\mathrm{N}$, en la que se conservaba un cipo de base rectangular que hacía ángulo con el supuesto Recinto o. 
uno y otro que con impedir expresamente el acceso a ellos.

Es muy posible que a la espalda de ambos se situara una tercera batería de acotados funerarios, a la que habrían pertenecido los Recintos o y p, este último mejor definido. Sin embargo, los problemas de modulación nos impiden llegar más allá. Y es que, como ya vimos, el Recinto L no sigue el módulo general de $12 \times 12$ pies delimitado por un número variable de cipos. Por el contrario, junto con $\mathrm{m}$ (vid. infra), del que parece gemelo en cuanto a dimensiones, conforma un gran espacio alargado en sentido $\mathrm{E}-\mathrm{O}$, cuya superficie in fronte $-15,30 \mathrm{~m}=51,75$ pies romanos- no es en absoluto múltiplo de 12 , rompiendo así el ritmo y haciendo poco probable que partiera de una lotización del terreno uniforme.

En la parte central del Recinto L se pudieron constatar restos de dos ustrina superpuestos. El de cronología más alta fue construido a su vez - sin afectarlos- sobre los Enterramientos 53-55, pertenecientes a una fase previa ${ }^{41}$; como ellos, rompía el pavimento de picadura de sillar de la vía y presentaba una acumulación de mampuestos en uno de sus lados cortos -el oriental-. Contenía cuando menos los restos de dos cremaciones separadas por una capa de arcilla. Entre las cenizas de la más antigua se recuperaron varios ungüentarios cerámicos y grandes fragmentos de la madera utilizada en la pira; entre las de la más reciente, varios ungüentarios de cerámica y una lucerna Dressel 2 de cronología tardorrepublicana (Morillo, 2015: 346). El segundo de los ustrina contenía los restos de una única cremación, sin material asociado.

Este acotado funerario proporcionó uno de los conjuntos más numerosos, ricos y variados de enterramientos, si bien, como acabamos de señalar un poco más arriba, no todos son coetáneos y es muy posible que, aun cuando no medie mucha distancia cronológica entre ellos, en algún caso pertenecieran a una fase previa. Unificándolos provisionalmente

41 No podemos, ni sería razonable descartar que estos y otros enterramientos pudieran haber sido dispuestos inicialmente en un espacio abierto, sin relación con recinto alguno. Esto explicaría sin problemas que en una fase posterior quedaran integrados en el subsuelo de algún acotado. en beneficio de la síntesis, hablamos de 7 cremaciones secundarias ${ }^{42}$ : en urna cerámica -Enterramientos 35 y 53-55-, en olla ossuaria de piedra -Enterramientos 39 y 64- y directamente en fosa, sin urna ni contenedor funerario alguno -Enterramiento 36-; y 2 inhumaciones: una en urna cerámica -Enterramiento $40-^{43}$ y otra entre dos tegulae -Enterramiento 37-44.

Las deposiciones más antiguas desde el punto de vista estratigráfico son los Enterramientos 39 y 64, en urna de piedra, y los 53-55, que comparten cota. En cuanto al resto es difícil por el momento establecer la seriación. Eso sí, la mayor parte de los materiales arqueológicos con cierta fiabilidad cronológica parecen remitir a la primera mitad del s. I d. C. Es el caso, por ejemplo, del Enterramiento 35, una cremación secundaria en urna cerámica protegida, a modo de cista, por un gran fragmento de ánfora, a la que acompañaba uno de los ajuares más ricos del sepulcretum: un ungüentario de vidrio; dos colgantes de pasta vítrea en forma de flor y de falo; tres formas de cerámica tipo Peñaflor, remontables en principio a época julioclaudia (Vargas, 2002: 1-3); un elemento de cobre en muy mal estado de conservación, y un scutum en miniatura trabajado sobre asta de ciervo. Destacan igualmente el Enterramiento 36, cremación secundaria en loculus que incluía como ajuar nueve piezas de cerámica tipo Peñaflor, dos cuencos de cerámica común, dos vasitos de paredes finas, una lucerna y un mínimo de 24 clavos metálicos; el Enterramiento 39: una cuenta de collar de cristal de roca, una posible lunula y varios fragmentos de hueso trabajado; y el Enterramiento 41, con 7 piezas de cerámica tipo Peñaflor.

En el interior del acotado fueron recuperadas además dos ánforas completas en sendas fosas, una en posición vertical y otra horizontal. La primera es una Haltern 71, cuya producción se fecha entre

42 Más una posible -Enterramiento 41- y el singular caso del Enterramiento 42: un loculus en el que fue enterrado un perro.

43 Llevaba como ajuar un cuenco de cerámica común similar a los del tipo 2.4 de los documentados en los Villares de Andújar (Peinado, 2010: 137 y 199).

44 Una tegula sirvió de lecho y la otra de cubierta. No incluía ajuar. 
el cambio de Era y finales de época tiberiana; la segunda, una Dressel 7-11, que lo hace entre época augústea y época flavia.

\subsection{Recinto $M$}

Es muy similar al Recinto L, con el que en principio compartiría datación algo más tardía, por haber ocupado un área inicialmente libre de acotados, pero no quizás de deposiciones. Quedaba delimitado por la vía, el cipo de su esquina so y los restos del pequeño muro de mampostería que habría compartido con aquel; aparte, por supuesto, de los termini que definen el Recinto N por su lado occidental, que le habrían servido de medianera por el E. Como en el caso anterior, es posible que lindara con una tercera batería de loci. Tampoco este sigue el esquema predominante de doce por doce pies; por el contrario, adopta una forma alargada que mantiene tal vez los 12 pies in agro, pero no in fronte, si tenemos en cuenta sus 15,30 m -51,75 pies romanos-.

En su interior, muy cerca de la fachada, fue practicada una tumba de cremación -Enterramiento 60- sobre la que se dispuso una estela/cipo de cabecera redondeada que acogió en su cara frontal el titulus sepulcralis que I. Iuventius Amarantus dedicó a su mujer Bassa sobre un fragmento de placa en mármol violáceo al parecer reaprovechado ${ }^{45}$; único ejemplo de estas características documentado en la necrópolis - cf. infra-. Por otra parte, en el tercio oriental del espacio funerario fue excavada una estructura de difícil interpretación que reaprovechó dos muros de mampostería de un ustrinum anterior ${ }^{46}$ y completó con un tercer tramo, siempre de la misma edilicia, hasta formar un pequeño pasillo en el que se constató una cierta acumulación de elementos cerámicos: en su mayoría cerámicas

45 Además de un fragmento de tegula como tapadera y otro cubriendo la fosa, la tumba incluyó junto a la urna un gran ungüentario del tipo Isings $28 \mathrm{~A}$, muy abundante en la segunda mitad del s. I d. C. (Salinas, 2003: 50).

46 Fosa de bordes rubefactados delimitada por pequeños muros de mampostería en sus lados meridional y oriental que apareció vacía y colmatada por un estrato de arcilla. tipo Peñaflor y una lucerna derivada de la Dressel 3. Todo ello estaba muy afectado por una gran fosa de cronología contemporánea.

El recinto proporcionó además una cremación directamente en fosa -Enterramiento 33-; cuatro más secundarias en urna cerámica -Enterramientos 31, 32, 49 y 60-, y dos inhumaciones infantiles: una en urna cerámica ${ }^{47}$-Enterramiento $34-$ y otra en ánfora cortada en sentido longitudinal -Enterramiento 51-, estas dos últimas sin ajuar. Con excepción del Enterramiento 33, todas las cremaciones presentaban uno o dos ungüentarios de vidrio en el interior de la olla ossuaria.

\subsection{Recinto $N$}

De 12 x 12 pies, estaba delimitado por seis cipos -caso único en el sepulcretum, lo que contribuye a enriquecer aún más la casuística-, cuatro en los ángulos y dos en sus laterales oriental y occidental, y limitaba con seguridad por su lado $\mathrm{N}$ con la que podría conformar una tercera serie de acotados -Recinto P-. En su interior se localizaron 10 enterramientos: cinco cremaciones secundarias en urna cerámica -Enterramientos 1-4 y 66-, una inhumación en urna cerámica -Enterramiento 5-, dos inhumaciones infantiles en ánfora -Enterramientos 18 y 19- y otra posible inhumación en ánfora -Enterramiento 17- con ajuar pero no restos humanos (Fig. 10); además de un perro inhumado en urna cerámica. Todos ellos se superponen, con una diferencia máxima de cota de hasta $1,25 \mathrm{~m}$, lo que parece abogar por un periodo de ocupación del espacio bastante dilatado en el tiempo. Destaca el Enterramiento 1, con un "ajuar tipo" (Vargas, 2002) conformado por nueve piezas de terra sigillata hispánica precoz -tipo Peñaflor- atribuibles a época julioclaudia: tres platos, tres vasos y tres vasitos colocados estratégicamente de forma secundaria en torno a la olla ossuaria una vez depuesta en tierra.

Por regla general las deposiciones funerarias presentan como único ajuar un ungüentario vítreo depositado dentro de la urna; solo el Enterramiento

47 A la que recortaron el borde para introducir el cadáver. 


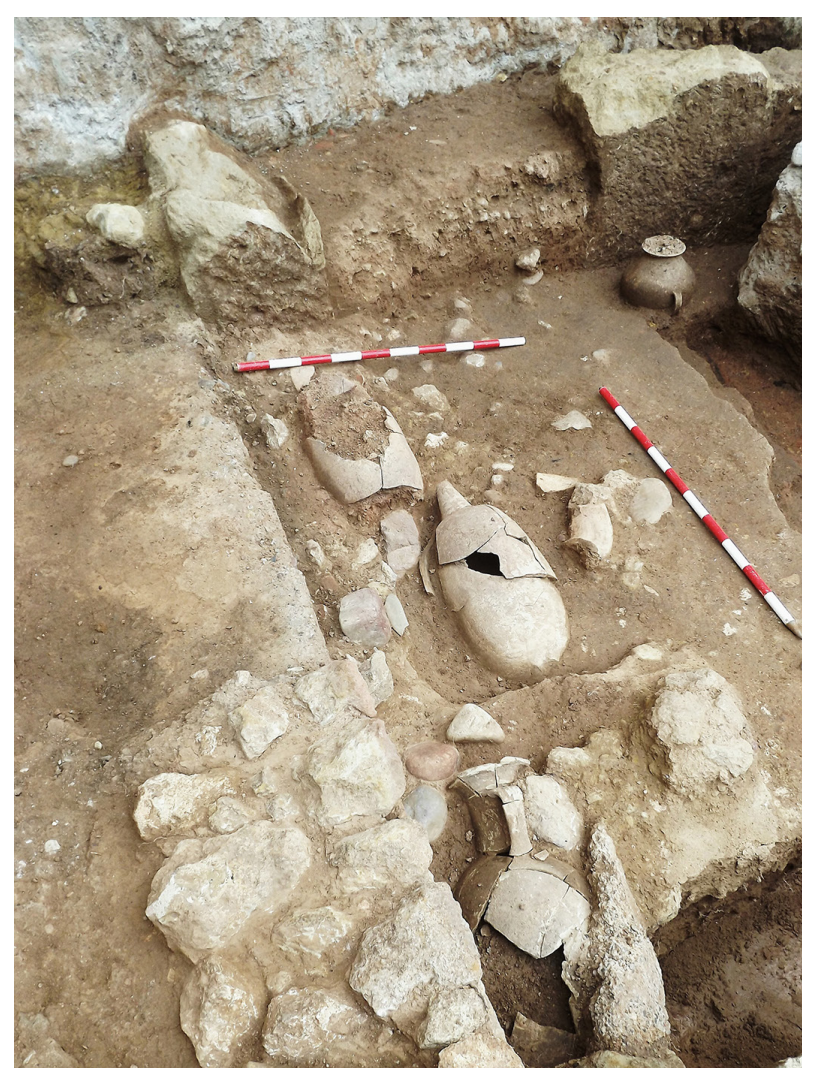

FIG. 10. Acumulación de ánforas usadas como contenedores funerarios en el lateral $N$ del Recinto Funerario $N$.

17, del que no se pudieron recuperar restos óseos quizás por haberse descompuesto completamente, incluía como ajuar una jarrita cerámica común de boca trilobulada similar a las del tipo 5.1 documentadas en los Villares de Andújar (Peinado, 2010: 141-142 y 208).

En la parte central del recinto se excavaron restos del ustrinum: fosa con los bordes rubefactados que contenía solo un relleno de arcilla con diverso material cerámico, sin estrato alguno de cremación, tal vez por haber sido vaciado. Su uso no debió ser muy dilatado en el tiempo; sobre él se dispusieron algunos enterramientos.

\subsection{Recinto $O$}

Se inscribe en la que consideramos tercera línea de recintos por el $\mathrm{N}$, que no podría sino abrir a una segunda vía, no documentada. Apenas se intuye su existencia a partir de su posible cipo suroriental y la localización en su interior de dos cremaciones secundarias en urnas superpuestas -Enterramientos $38^{48}$ y $62^{49}$ - que, como es habitual, buscan su abrigo. La distancia que lo separa del Recinto P no es múltiplo de 12 .

\subsection{Recinto P}

Ubicado en el extremo oriental del sepulcretum, es el único ejemplo claro atribuible a la tercera línea de recintos funerarios que darían fachada a una segunda vía o espacio abierto de características indeterminadas ubicados más al N. Se dispone de hecho a espaldas del Recinto N, y al igual que C, F, I y K cerró el locus, presumiblemente de 12 × 12 pies y delimitado por

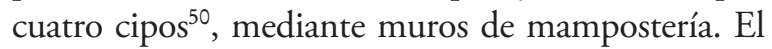
pequeño espacio interior que no había sido afectado por interfacies posteriores estaba pavimentado con nódulos calizos de pequeño tamaño y no disponía de ustrinum. Solo se pudo recuperar en él una cremación secundaria en urna cerámica protegida por un lebrillo (Enterramiento 47), con 36 cuentas de collar de pasta vítrea, 2 bullae broncíneas, una varilla metálica de bronce, una lámina de hueso trabajado y un elemento de cobre muy mal conservado en el interior de la olla ossuaria.

\section{Recapitulación}

Hemos presentado en las páginas precedentes un nuevo sepulcretum documentado merced a sendas

48 El Enterramiento 38 se superponía al 62. Incorporaba un gran fragmento de cerámica común colocado a modo de cista de protección y calzado con un trozo de revestimiento parietal pintado de procedencia indeterminada, e incluía como ajuar, en el interior de la urna, un ungüentario de vidrio dentro de un vasito de paredes finas del tipo cáscara de huevo.

49 También este último, cremación en olla ossuaria dispuesta en cista simple, contenía como único ajuar el consabido ungüentario vítreo depositado junto a los huesos cremados.

50 No pudo ser excavado completo porque se introducía en el perfil $\mathrm{N}$. 
intervenciones arqueológicas preventiva y de urgencia localizadas en el marco de los límites de la que fue "necrópolis septentrional" de la Colonia Patricia de principios del Imperio, en una zona inmediata a la confluencia del Camino del Pretorio y la via Corduba ab Emerita Augusta; un sector funerario que destaca por su marcada planificación; por el predominio del módulo de $12 \times 12$ pies en los loci sepulcrorum documentados, y por su compleja topografía, estructurada de manera diacrónica con fines estrictamente cementeriales en torno a uno o varios diverticula trazados ex profeso. Deja constancia así, una vez más, de la densidad y riqueza que llegó a alcanzar el paisaje funerario romano de principios del Imperio en la capital de la Bética, de fuerte impronta itálica por más que muchos de los enterramientos se sirvan para acoger los restos óseos de urnas cerámicas de supuesta tradición indígena (García Matamala, 2002; García Matamala y Liébana, 2006; Jiménez Díez, 2008), cuyas verdaderas filiación y problemática constituyen uno de los retos más destacados de futuro para la investigación cordobesa sobre el mundo funerario ${ }^{51}$.

La mayor parte de los recintos utilizaron como señalizadores de su respectivo locus un número indeterminado -mayoritariamente 4 , aunque no falta alguno con 6 y es posible que los hubiera con menos- de cipos de piedra calcarenita de morfología desigual, tal como observamos ya en el conjunto de la avda. de las Ollerías, algunos de ellos con la cabecera redondeada. Dicha circunstancia parece confirmar la idea que apuntábamos más arriba: el propietario o promotor -público o privado, eso habría que determinarlo- parcelaba el terreno y lo vendía modulado, pero la iniciativa de señalizarlo correspondía seguramente al comprador. De ahí la diversidad observada. Es difícil afirmarlo, no obstante, debido a la acción en la estratigrafía de procesos posdeposicionales traumáticos que en

51 Al respecto $c f$. también la dinámica detectada en Baelo Claudia y la Silla del Papa: algunas de las urnas cerámicas utilizadas en la necrópolis de este último yacimiento coinciden con las primeras, de época augústea, que se documentan después en la nueva ciudad romana (Moret et al., 2017: 61 y ss.). múltiples ocasiones han desconfigurado por completo el paisaje funerario inicial.

Completan la casuística aquellos acotados -Recintos F y G- que incluyeron en alguno de los cipos un titulus con las mensurae sepulcri-paradójicamente en su fachada trasera y mirando al interior del espacio, no a la vía (Fig. 11)-; los que cerraron su contorno mediante muros de mampostería de diferente entidad y alcance-Recintos C, F, I, K, P y quizás también el A- ${ }^{52}$, o aquellos otros que dispusieron varios cipos en fachada unidos mediante muros de tapial revocados y baja altura -Recintos L y M-. Solo los Recintos C y F han conservado en fachada puertas más o menos monumentalizadas, dotadas en ambos casos de un escalón descendente, lo que permite deducir que el nivel original de los acotados se encontraba por debajo del de la calle (Fig. 12). En los otros tres cerrados con muros de fábrica no han aparecido huellas de vanos ${ }^{53}$, y los demás podrían haber quedado abiertos, marcados quizás mediante algún tipo de elemento vegetal o que, en cualquier caso, no nos ha llegado.

La práctica totalidad de los recintos contaba en su interior con uno o varios ustrina por lo general en fosa simple $e^{54}$, aunque no faltan algunos delimitados por muros de mampostería y huellas claras casi siempre de haber acogido una o varias cremaciones. Con frecuencia entre las cenizas, separadas por capas de cal o de arcilla, aparecieron ungüentarios cerámicos -de los 94 recuperados solo alguno presentaba huellas de fuego, por lo que es posible que se quemara con el difunto el contenido, pero no

52 El hecho de que no haya un solo caso de recintos que compartan medianeras viene a confirmar una vez más que cada uno de ellos siguió su propia dinámica, gobernada sin duda por las necesidades, las conveniencias o los deseos de sus propietarios. Esto hace que no se puedan establecer normas.

53 En el caso del Recinto $\mathrm{K}$, porque en el lugar en el que supuestamente estaría aparece un pozo negro califal que destruye la zona. En el de los Recintos A, I y P, porque su posición con respecto a los límites del solar ha impedido documentar la zona en la que deberían situarse estos vanos.

54 Destacan en este sentido el Recinto L, con dos quemaderos, el primero de ellos construido ya sobre tres enterramientos anteriores, y el Recinto E, donde fueron documentados tres superpuestos. 


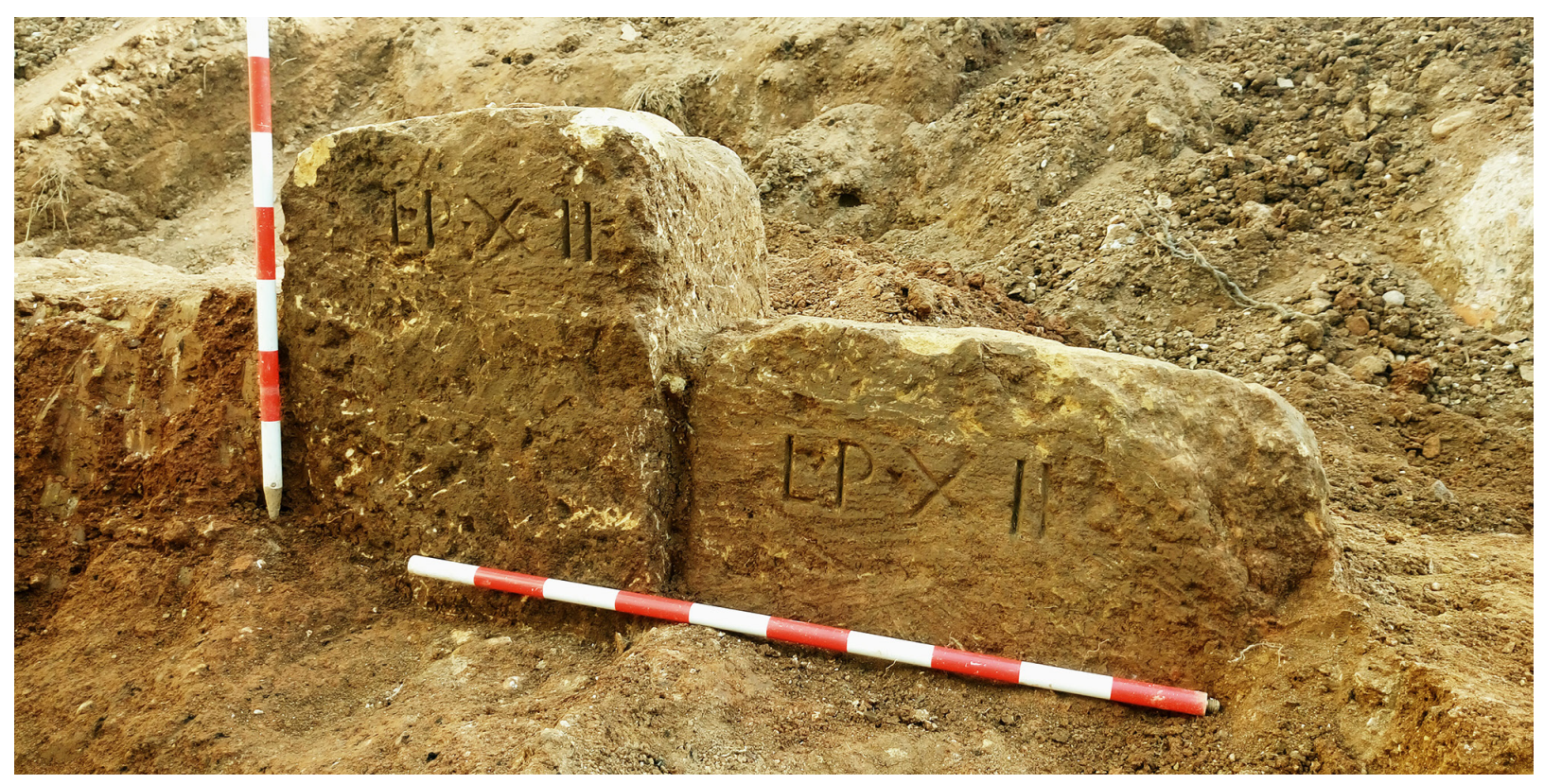

Fig. 11. Detalle de los dos cipos con indicatio pedaturae documentados en la intervención.

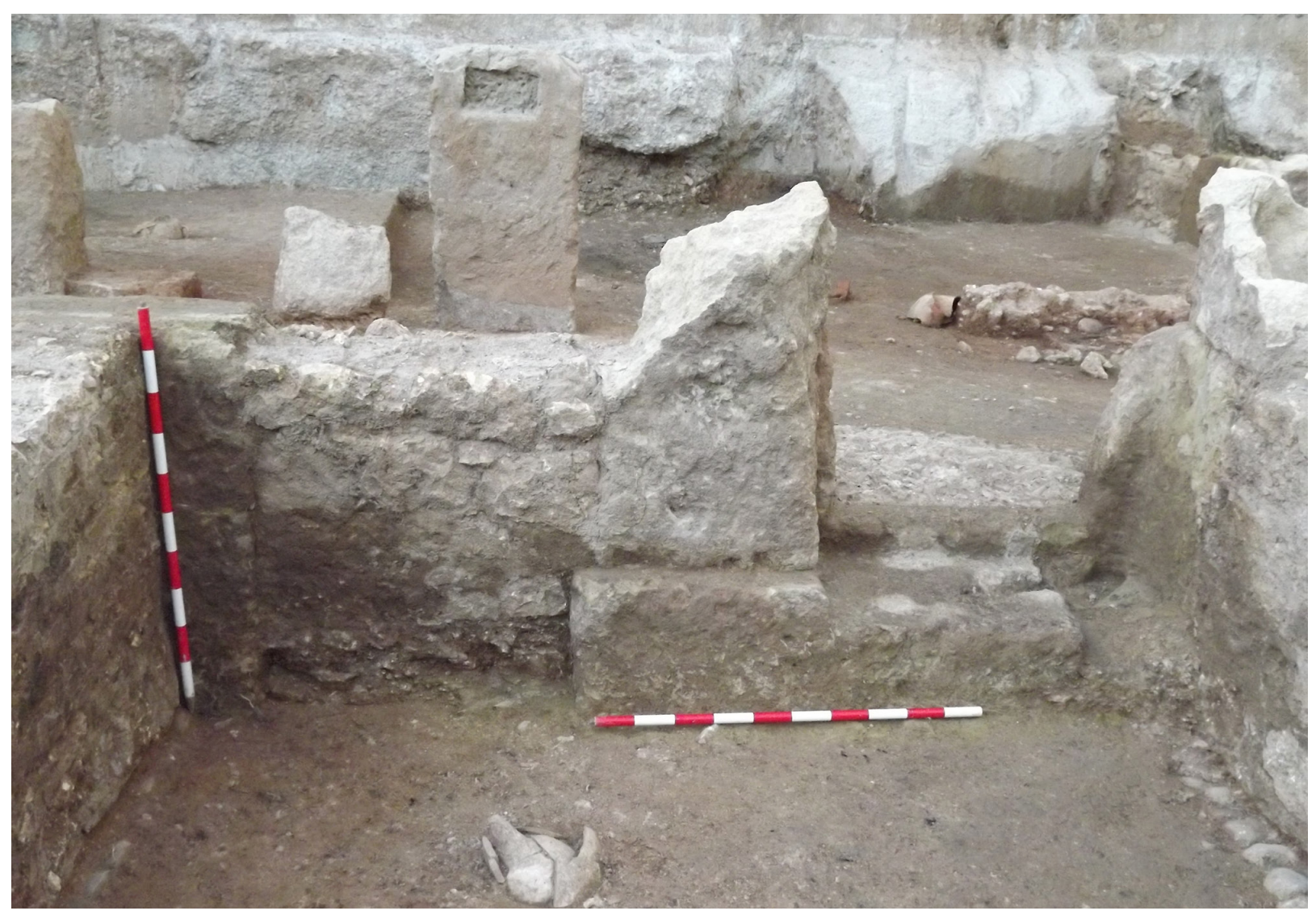

FIG. 12. Escalón de entrada al Recinto Funerario F. 
el contenedor- y lucernas, en algún caso de época tardorrepublicana, lo que abunda en nuestra idea de que la necrópolis pudiera haber arrancado, al menos en su concepción y primer trazado, de un momento cercano al cambio de Era.

Esto resulta especialmente evidente en el caso del Recinto L. La fosa del primero de sus ustrina fue excavada, sin afectarlas, sobre las Tumbas 53-55, de una fase previa. Pues bien, si los ungüentarios y la lucerna abandonados entre las cenizas de la segunda de las cremaciones practicadas en él remiten a la segunda mitad del s. I a. C. (Morillo, 2015: 346), y ya existían tres deposiciones previas que a su vez rompían el pavimento de la vía y supuestos espacios libres, no parece descabellado remontar la lotización del terreno, la construcción del diverticulum, la venta de los primeros recintos y los primeros enterramientos al último cuarto del s. I a. C. Con todo, esta cronología provisional habrá de ser progresivamente matizada conforme avancen los estudios del material cerámico ${ }^{55}$.

Los Recintos A, D, F, I, K y P no disponían de quemaderos, si bien podrían haber desaparecido como consecuencia de los procesos posdeposicionales. De hecho, en el último de ellos algunas huellas de rubefacción en su cipo SE y las cenizas dispersas en los niveles de colmatación parecen confirmar que en algún momento acogió fuego. A tenor de la documentación arqueológica, las cremaciones se practicaron mayoritariamente en el interior de los acotados, tanto si permanecieron abiertos como si se tapiaron, y a pesar de su escaso tamaño. No sería fácil alimentar las piras en un espacio tan reducido sin dañar a vecinos, enterramientos previos o cipos, paredes y cierres, sobre todo en el caso de que estos hubieran sido de materia orgánica.

De entrada, la cremación se habría reservado a personas adultas. Lo normal en todo el Imperio fue inhumar a los niños que morían antes de la dentición (Plinio, Nat. Hist. vII, 15) ${ }^{56}$; así ocurrió

55 A cargo de L. Hernández y S. Vargas.

56 Algunos autores interpretan esta práctica como un aspecto diferencial más del ritual funerario aplicado a los immaturi, cuyo carácter maléfico, o nefasto, debía ser conjurado mediante pasos muy tipificados (Baills-Talbi y Dasen, también de forma mayoritaria en Hispania, donde eventualmente debieron ocupar áreas específicas reservadas para ellos, como se observa, por ejemplo, en necrópolis galorromanas (Durand, 2008), y uno de nosotros ha sugerido para el caso de Córdoba (Vaquerizo, 2010: 127 y ss.). Sin embargo, no todos los niños en Roma fueron enterrados conforme al rito inhumatorio. En esto también hubo excepciones. Así lo observamos, por ejemplo, en Altinum, donde los immaturi fueron cremados y sus huesos recogidos en urnas vítreas, con ajuares de gran contenido simbólico en los que abundan las figurillas de terracota (Tirelli, 2001: 247); o en la propia Corduba, donde ardieron en las piras sobre lechos funerarios de cierta riqueza muy cerca de Llanos del Pretorio, y con cronologías que parten de la primera mitad del s. I d. C. (Penco et al., 1993: 47 y 54; estructura funeraria 11; Morena, 1994: 160-161 y Penco, 1998: 68 y ss., tumba vi). En el caso concreto de Llanos del Pretorio, y a expensas de lo que diga el informe definitivo de los especialistas, la inhumación se reservó en particular a recién nacidos e individuos perinatales (Fig. 13).

Las inhumaciones no suelen llevar ajuar, y cuando lo hacen suele tratarse de una pieza de cerámica común tipo jarra o cuenco, de acuerdo con claves rituales gobernadas en buena medida por el pragmatismo. Recordemos que la revalorización de la muerte infantil no se produce hasta mediados del s. I d. C. (Vaquerizo, 2010: 313).

Con independencia del tipo de ritual, todos los enterramientos fueron practicados en fosas simples, abiertas directamente en tierra, y en algunos casos los contenedores funerarios se protegieron con círculos de mampuestos o fragmentos de ánfora. Nueve de las inhumaciones utilizaron como contenedores ánforas cortadas longitudinalmente (Pereira y Alburquerque, 2018); tres, urnas cerámicas, y otra más se sirvió de sendas tegulae. Por su parte, las cremaciones usaron ollae ossuariae de vidrio -Enterramiento 44-; urnas de piedra con patas más o menos marcadas y tapas en forma de tejado a dos aguas, evocando, sin duda, la forma 2008: 601); cf. también Fernández Martínez, 2006; Gómez Pallarés, 2009, o Sevilla, 2014, con bibliografía anterior. 

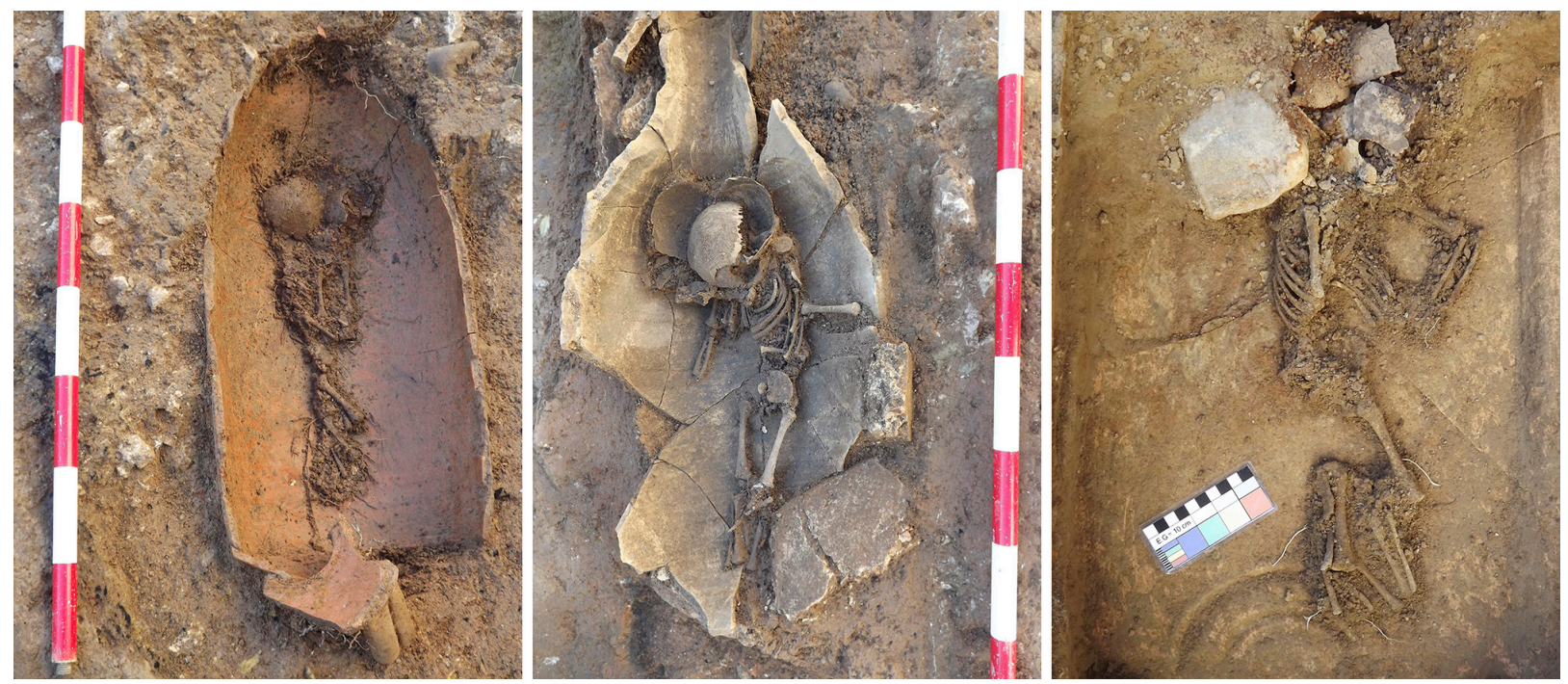

FIG. 13. Algunas de las inhumaciones perinatales documentadas en la intervención: de izquierda a derecha Enterramientos 51, 50 y 37.

de la cabańa o de la casa, entendida la tumba como domus aeterna -Enterramientos 39, 43, 52, 59 y 64-, y urnas cerámicas a torno -45 ejs.-, buena parte de ellas con asas y decoración pintada a bandas (Fig. 14).

De los 67 enterramientos recuperados, 36 presentaban ajuar, lo que supone un $53,7 \%$ del total. Cuando el rito empleado fue la cremación, cabe distinguir entre ajuar primario, secundario y terciario, que en cualquier caso parecen demostrar un predominio absoluto del ungüentario vítreo o cerámico como pieza única ${ }^{57}$. Los de vidrio han sido documentados en un total de 23 enterramientos -2 , 4, 12, 23, 26, 27-в, 28, 29, 31, 32, 35, 38, 43, 44, 45, 46-A, 49, 56, 58, 59, 60, 62 y 64-, en solitario o combinados con otros elementos. En el caso concreto de las cremaciones depositadas en urnas de piedra los balsamarios son siempre del tipo Isings $6 / 26$, pero en el resto de casos menudean los tipos Isings 8, 27 y $28 \mathrm{~A}$.

No faltan ajuares tipo Peñaflor -Enterramientos 1, 35, 36, y 41- (Fig. 15), que suelen formar juegos de 3, 6 o 9 vasos -el Enterramiento 41 proporcionó 7-; alguna pieza de cerámica común tipo jarra

57 Cerámico hay un solo caso -Enterramiento 16-. De entre los vítreos, presentaban huellas de fuego las piezas recuperadas en los Enterramientos 31 y 46-A.
-Enterramiento 9- o cuenco -Enterramiento 36que en ocasiones acompañan también a las inhumaciones infantiles -Enterramientos 17 y 40-, y ajuares mucho más complejos como los presentes en los Enterramientos 35 y 36, que incluían cerámica de paredes finas ${ }^{58}$, alguna joya de pasta vítrea 0 cristal de roca ${ }^{59}$, hueso o asta trabajados, y elementos metálicos diversos de difícil identificación. Solo el Enterramiento 7 proporcionó 1 moneda, y el 36 un conjunto de 24 clavos de hierro que en principio cabría atribuir al lectus o feretrum en el que fue quemado el difunto. Alguna de las deposiciones - caso del Enterramiento 8 en el Recinto B- incluía algo de malacofauna con huellas de fuego, quizás restos de un banquete o posible símbolo profiláctico. Finalmente, el ánfora que protegía la urna de vidrio del Enterramiento 44 sirvió también como canal de libaciones, tapada su boca al efecto con un cuenco de cerámica común.

58 Enterramiento 36: dos formas 8c (Tiberio-Claudio); Enterramiento 38: una forma 34в (Tiberio-primer decenio flavio) (López Mullor, 2008: 367).

59 Enterramiento 35: dos colgantes de pasta vítrea en forma de flor y de falo; Enterramiento 39: cuenta de collar de cristal de roca; Enterramiento 47: 36 cuentas de collar en pasta vítrea, de diferentes tamańos y colores. Los dos primeros se integraban en el Recinto L; el tercero en el Recinto P. 

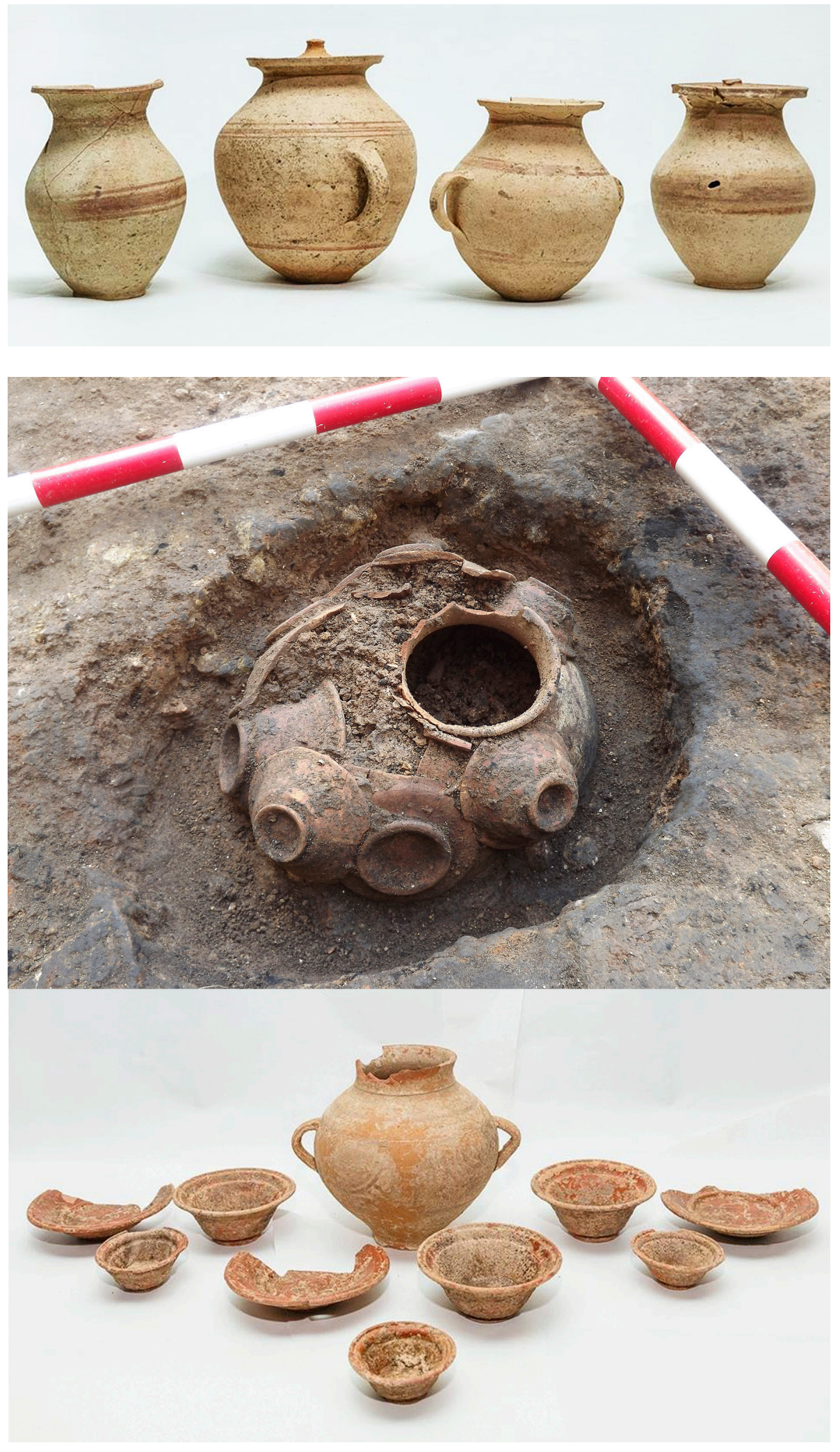

FIG. 14.

Selección de urnas cinerarias con decoración pintada a bandas documentadas en el Recinto Funerario G.
FIG. 15.

Ajuar tipo Peñaflor que acompañaba al Enterramiento 1, antes $y$ después de su extracción. 
A la vista de la documentación analizada, el sepulcretum de Llanos del Pretorio no representa un unicum en el panorama arqueológico funerario hispano, ni siquiera cordubense. Ya hablamos más arriba de los conjuntos de Ollerías ${ }^{60}$ y La Constancia (Vaquerizo et al., 2005), a los que podrían sumarse otros como Camino Viejo de Almodóvar (Ruiz Osuna, 2005), avda. del Corregidor (Vargas y Gutiérrez, 2004 y 2006; Vaquerizo, 2010: 108 y ss.; Ruiz Osuna, 2007: 2010 y 2014), o cl Abderramán III-Centro de Salud Huerta de la Reina (Salinas Pleguezuelo, 2015); y no debemos olvidar el uso recurrente, y cargado de sugerencias históricas, sociales e ideológicas, de indicatio pedaturae en ciudades como Astigi, Augusta Emerita (Vaquerizo y Sánchez, 2008; Vaquerizo, 2010) o Segobriga (Cebrián y Hortelano, 2016). En esta última la excavación de su necrópolis noroccidental, bajo el circo, dejó al descubierto una dinámica funeraria de época altoimperial muy similar a la del Pretorio, con una alta representación entre los enterrados de esclavos y de libertos. A día de hoy, con todos los matices que se quiera, se erige de entrada como su mejor paralelo hispano fuera del caput Baeticae.

A la espera de los estudios geológicos y de la revisión de otras intervenciones arqueológicas próximas, todo parece indicar que el excepcional estado de conservación del sepulcretum de Llanos del Pretorio obedece a que una posible arroyada procedente de un curso de agua cercano lo anegó por completo, sellándolo con un estrato de limos $-0,63$ $\mathrm{m}-$. Tras la crecida y su consiguiente anegamiento, la zona no volvería a ser ocupada hasta época califal - s. X-. Su vida útil fue, pues, bastante breve, centrada a nuestro juicio entre el último cuarto del s. I a. C. e inicios de la dinastía flavia, cronología provisional avalada por la cerámica documentada tanto en las colmataciones de los recintos como en los ajuares, que habrá aún de ser precisada. Entre la primera destaca la presencia de sigillata itálica, gálica y marmorata. La ausencia de sigillata hispánica parece indicar que la necrópolis habría quedado inutilizada en fechas anteriores a la comercialización y expansión de este tipo de cerámica.

60 López Jiménez, op. cit. n. 3.
En cualquier caso, este es solo el primer avance de una investigación colectiva, a cargo de un equipo multidisciplinar e interuniversitario, que verá la luz de manera monográfica en fecha próxima. Esto ha sido posible solo merced a la colaboración entre el arqueólogo que dirigió la intervención y la Universidad de Córdoba. El rigor y la exhaustividad en los trabajos de excavación han permitido poner en marcha un proyecto ad hoc, cuyos resultados marcarán seguramente un antes y un después en la forma de acercamiento al hecho funerario corduben$s e$; en una prueba más de que arqueología profesional y arqueología académica deben, ineludiblemente, caminar unidas (Vaquerizo, 2018).

\section{Bibliografía}

AlfaYé, S. (2009): "Sit tibi terra gravis: magical-religious practices against Restless dead in the ancient world". En Marco, F.; Pina, F. y Remesal, J. (eds.): Formae mortis: el tránsito de la vida a la muerte en las sociedades antiguas. Barcelona, pp. 181-215.

Alfayé, S. (2016): "Los temores del mago. Miedos en torno a la acción mágica en la antigua Roma”. En Alfayé, S. (ed.): Verenda numina: temor y experiencia religiosa en el mundo antiguo. Arys, 14. Madrid, pp. 109-152.

Arévalo, A. (ed.) (2016): Monedas para el más allá. Uso y significado de la moneda en las necrópolis tardopúnicas y romanas de Ebusus, Gades y Malaca. Cádiz-Málaga.

Baills-TAlbi, N. y Dasen, V. (2008): "Rites funéraires et pratiques magiques". En Gusi, F.; Muriel, S. y Olaria, C. (coords.): Nasciturus, Infans, Puerulus vobis Mater Terra. La muerte en la infancia. Castellón, pp. 595-618.

Baldasarre, I. (2002): "La necropoli dell'Isola Sacra". En Vaquerizo, D. (ed.): Espacio y usos funerarios en el Occidente romano. Córdoba, vol. II, pp. 11-26.

Calza, G. (1940): La necropoli del Porto di Roma nell'Isola Sacra. Roma.

Cánovas, A.; Sánchez, S. y Vargas, S. (2006): "La tumba de Caius Pomponius Statius en la necrópolis septentrional de Colonia Patricia", Anales de Arqueologia Cordobesa, 17, pp. 279-296.

Cebrián, R. y Hortelano, I. (2016): Segobriga Vi. La necrópolis noroccidental de Segobriga (Saelices, Hispania Citerior). Arquitectura funeraria, organización espacial y cronología. Cuenca. 
Cennerini, F. (2005): "L'indicazione della pedatura nelle iscrizioni funerarie romane dell'Emilia Romagna (Regio viit)". En Cresci, G. y Tirelli, M. (eds.): "Terminavit Sepulcrum". I recinti funerari nelle necropoli di Altino. Roma, pp. 137-143.

DorTez, T. (2008): "Intervención arqueológico preventiva en la Parcela Dotacional 3.1. del Plan Parcial Renfe". En Anuario Arqueológico de Andalucía 2008. Sevilla, pp. 1322-1326.

Durand, R. (2008): "Données paléodemographiques et classes d'âge immatures: recrutement et gestion des enfants dans les espaces funéraires gallo-romains". En Gusi, F.; Muriel, S. y Olaria, C. (coords.): Nasciturus, Infans, Puerulus vobis Mater Terra. La muerte en la infancia. Castellón, pp. 41-56.

Fernández Martínez, C. (2006): "Los adjetivos latinos relacionados con acerbus. Significado original y derivaciones metafóricas", Emerita, LXXIV (1), pp. 113-144.

Fernández Martínez, C. (2007): Carmina latina epigraphica de la Bética romana. Las primeras piedras de nuestra poesía. Sevilla.

García Matamala, B. (2002): "Enterramientos con urnas de tradición indígena en Corduba". En VAQUerIzo, D. (ed.): Espacio y usos funerarios en el Occidente romano. Córdoba, vol. II, pp. 275-296.

García Matamala, B. y Liébana, J. L. (2006): "Inhumaciones infantiles de tradición indígena en un sector de la necrópolis oriental de Corduba". En Vaquerizo, D.; Garriguet, J. A. y León, L. (eds.): Espacio y usos funerarios en la ciudad histórica. Córdoba, vol. I, pp. 99-114.

García-Dils, S. y Rubio, M. (2018): “Tres nuevas defixiones en su contexto arqueológico. La necrópolis de Llanos del Pretorio (Córdoba)", Anales de Arqueología Cordobesa, 29, pp. 263-292.

Gómez Pallarés, J. (2009): "Las cuatro estaciones como símbolo funerario en la cultura escrita y visual de Roma: una aproximación”. En Fernández Martínez, C. y Gómez Pallarés, J. (eds.): Literatura epigráfica. Estudios dedicados a G. Sanders. Zaragoza, pp. 155-187.

Gros, P. (2001): L'architecture romaine du debut du IIIe. siècle av. J.-C. à la fin du Haut-Empire. 2. Maisons, palais, villas et tombeaux. Paris.

Heinzelmann, M. (2000): Die Nekropolen von Ostia. Untersuchungen su den Gräberstrassen vor der Porta Romana und an der Via Laurentina. München.

IвÁÑEZ, A. (1990): "Intervención arqueológica de urgencia en Ronda de los Tejares 6 de Córdoba". En Anuario Arqueológico de Andalucía 1987. Sevilla, vol. III, pp. 176-181.

(C) Universidad de Salamanca
JimÉnez DíEz, A. (2008): Imagines Hibridae. Una aproximación postcolonialista al estudio de las necrópolis de la Bética. Madrid.

Liébana, J. L. y Ruiz Osuna, A. B. (2006): "Los monumentos funerarios de la Plaza de la Magdalena: un sector de la necrópolis oriental en Corduba”. En Vaquerizo, D.; Garriguet, J. A. y León, L. (eds.): Espacios y usos funerarios en la ciudad histórica. Córdoba, vol. I, pp. 297-324.

López Mullor, A. (2008): "Las cerámicas de paredes finas en la fachada mediterránea de la Península Ibérica y las Islas Baleares". En Bernal D. y Ribera, A. (eds.): Cerámicas hispanorromanas: un estado de la cuestión. Cádiz, pp. 343-384.

MarfiL, P. (1997): “Intervención arqueológica de emergencia en el n. ${ }^{\circ} 14$ de la Avenida de las Ollerías (Córdoba)". En Anuario Arqueológico de Andalucía 1993. Sevilla, vol. III, pp. 149-160.

Melchor, E. (2004): "El territorio". En DuprÉ, X. (ed.): Las Capitales Provinciales de Hispania 1. Córdoba. Colonia Patricia Corduba. Roma, pp. 105-117.

Melchor, E. (2006a): "Hic ordo decrevit. honores fúnebres en las ciudades de la Bética". En Vaquerizo, D.; Garriguet, J. A. y León, L. (eds.): Espacio y usos funerarios en la ciudad histórica. Córdoba, vol. I, pp. 115-144.

Melchor, E. (2006b): "Solo publico-solo suo. Sobre la ubicación de los homenajes estatuarios en las ciudades de la Bética", Cahiers Glotz, xvII, pp. 201-211.

Monterroso, A. (2002): "La secuencia estratigráfica. Evolución histórica del teatro de Colonia Patricia". En Ventura, Á.; Márquez, C. y Carmona, M. A. (eds.): El teatro romano de Córdoba. Córdoba, pp. 133-146.

Morena, J. A. (1994): "Nuevas aportaciones sobre el Aqua Vetus Augusta y la necrópolis occidental de Colonia Patricia Corduba", Anales de Arqueología Cordobesa, 5, pp. 155179.

Moret, P.; Prados, F.; Fabre, J. M.; Fernández Rodríguez, E; García Fernández, F. J.; González, F. y Jiménez Vialás, H. (2017): "La Silla del Papa. Hábitat y necrópolis. Campañas 2014-2016”. En Brassous, L. y Lemaitre, S. (coords.): La ville antique de Baelo, cent ans après Pierre Paris. Madrid, pp. 49-71.

Morillo, A. (2015): "Lucernas romanas en Hispania: entre lo utilitario y lo simbólico". En FernÁNDEZ Ochoa, C.; Morillo, Á. y Zarzalejos, M. (eds.): Manual de cerámica romana II. Cerámicas romanas de época altoimperial en Hispania. Importación y producción. Madrid, pp. 321-428. 
Murillo, J. F. y Carrillo, J. R. (1999): “Aspectos de la monumentalización de las necrópolis de Colonia Patricia. El monumento funerario de Puerta de Gallegos". En Ciudades privilegiadas en el Occidente romano. Sevilla, pp. 365-378.

Murillo, J. F.; Carrillo, J. R.; Moreno, M. y Vargas, S. (2002): "Los monumentos funerarios de Puerta de Gallegos. Colonia Patricia Corduba". En Vaquerizo, D. (ed.): Espacio y usos funerarios en el Occidente Romano. Córdoba, vol. II, pp. 247-274.

Ortalli, J. (1987): "La via dei sepolcri di Sarsina. Aspetti funzionali, formali e sociali". En Von Hesberg, H. y ZANKer, P. (eds.): Römische Gräberstrassen. Selbstdarstellung-Status-Standard. München, pp. 155-182.

Peinado, M. V. (2010): Cerámicas comunes romanas en el alto Guadalquivir: el alfar de los Villares de Andújar. Granada.

Penco, F. (1998): "Un conjunto funerario de libertos y esclavos de época altoimperial excavado en la calle El Avellano, n. ${ }^{\circ} 12$ de Córdoba. Una nueva aportación a Colonia Patricia Corduba", Antiquitas, 9, pp. 61-77.

Penco, F.; Marfil, P.; Blanes, C. y Baena, M. D. (1993): "Resultados del estudio de la necrópolis romana excavada durante las dos fases de intervención arqueológica de urgencia desarrolladas en la Avenida de las Ollerías n. ${ }^{\circ} 14$ de Córdoba”, Antiquitas, 4, pp. 45-56.

Pereira, C. y Alburquerque, P. (2018): "Inumaçóes infantis em ânfora na Península Ibérica durante a época romana: a prática e o rito", Spal, 27 (1), pp. 89-118.

Prados, F. (2017): "La semántica de los símbolos. Prácticas funerarias en la necrópolis de Baelo Claudia". En Brassous, L. y Lemaître, S. (coords.): La ville antique de Baelo, cent ans après Pierre Paris. Madrid, pp. 73-96.

Purcell, N. (1987): “Tomb and Suburb”. En Hesberg, H. von y Zanker, P. (eds.): Römische Gräberstrassen. Selbstdarstellung-Status-Standard. München, pp. 25-42.

Py, M. (1993): "Unguentariums". En Py, M. (ed.): Dictionnaire des céramiques antiques (VIIe s. av. n. è-VIIe s. de n. è.) en Méditerranée nord-occidentale (Provence, Languedoc, Ampurdan). Lattara, 6. Lattes, pp. 581-584.

Ruiz Osuna, A. B. (2005): "La via sepulchralis occidental, ejemplo de monumentalización del espacio funerario en Colonia Patricia", Anales de Arqueología Cordobesa, 16, pp. 79-104.
Ruiz Osuna, A. B. (2006): "Arquitectura funeraria en la Bética: el ejemplo de las capitales conventuales”, Anales de Arqueología Cordobesa, 17, pp. 157-194.

Ruiz Osuna, A. B. (2007): La monumentalización de los espacios funerarios en Colonia Patricia Corduba (ss. I a. C.-II d. C.). Córdoba.

Ruiz Osuna, A. B. (2010): Colonia Patricia: centro difusor de modelos. Topografía y monumentalización funeraria en Baetica. Córdoba.

Ruiz Osuna, A. B. (2014): "Monumentalización funeraria en ámbito urbano: vías de interpretación aplicadas a la Córdoba romana”. En VAQuerizo, D.; GARRIGUET, J. A. y LEÓN, L. (eds.): Ciudad y territorio: transformaciones materiales e ideológicas entre la época clásica y el Altomedioevo. Córdoba, pp. 55-67.

Salinas Pleguezuelo, E. (2003): El vidrio romano de Córdoba. Córdoba.

Salinas Pleguezuelo, E. (2015): "Nuevos hallazgos exhumados en una necrópolis romana del sector septentrional de Córdoba (España)", Nailos, 2, pp. 253-273.

Sevilla, A. (2014): Funus Hispaniense. Espacios, usos y costumbres funerarias en la Hispania romana. Oxford.

Sillières, P. (1990): Les voies de communication de l'Hispanie meridionale. Paris.

STYLow, A. U. (1995): "Los inicios de la epigrafía latina en la Bética. El ejemplo de la epigrafía funeraria". En Beltrán, F. (ed.): Roma y el nacimiento de la cultura epigráfica en Occidente. Zaragoza, pp. 219-238.

TAglietTi, F. (2001): "Ancora su incinerazione e inumazione: la necropoli dell'Isola Sacra”. En Heinzelmann, M.; Ortalli, J.; Fasold, P. y Witteyer, M. (eds.): Culto dei morti e costumi funerari romani. Wiesbaden, pp. 149-158.

TiRelli, M. (2001): “...ut... largius rosae et esc[a]e... poneretur. I rituali funerari ad Altinum tra offerte durevoli e deperibili”. En Heinzelmann, M.; Ortalli, J.; Fasold, P. y WitTeyer, M. (eds.): Culto dei morti e costumi funerari romani. Wiesbaden, pp. 243-253.

Vaquerizo, D. (2010): Necrópolis urbanas en Baetica. Sevilla-Tarragona.

Vaquerizo, D. (2013): “Topography, monumentalization and funerary customs in an urban necropolis in Baetica", Journal of Roman Archaeology, 26, pp. 209-242.

VAQUerizo, D. (2014): “Mortes singulares y miedo a los muertos en el mundo romano. Reflexiones, indicios, escatología”. En Neira, L. (coord.): Religiosidad, rituales y prácticas mágicas en los mosaicos romanos. Madrid, pp. 211-246. 
Vaquerizo, D.; Garriguet, J. A. y Vargas, S. (2005): La Constancia. Una contribución al conocimiento de la topografía y los usos funerarios en la Colonia Patricia de los siglos iniciales del Imperio. Córdoba.

VAQUerizo, D. y SÁNCheZ, S. (2008): “Entre lo público y lo privado. La indicatio pedaturae en la epigrafía funeraria hispana", Archivo Español de Arqueología, 81, pp. 101-131.

VARGAS, S. (2002): "El conjunto funerario de la Constancia (Córdoba). Ajuares y cronología”. En VAQuerizo, D. (ed.): Espacios y usos funerarios en el Occidente romano. Córdoba, vol. II, pp. 297-310.

Vargas, S. y Gutiérrez, M. I. (2004): "Un ejemplo de los usos y costumbres funerarias de la Córdoba romana a través de un conjunto de tumbas de la necrópolis de la Avenida del Corregidor (Córdoba)", Anales de Arqueologia Cordobesa, 15, pp. 309-328.

VARGAS, S. y GutiérReZ, M. I. (2006): "La necrópolis romana de la Avenida del Corregidor de Córdoba”. En Vaquerizo, D.; Garriguet, J. A. y León, L. (eds.): Espacios y usos funerarios en la ciudad histórica. Córdoba, vol. I, pp. 259-278.

Ventura, Á. (1993): "Susum ad montes S(ocietatis) S(isaponensis): nueva inscripción tardorrepublicana en Corduba", Anales de Arqueología Cordobesa, 4, pp. 49-61.

Ventura, Á. y Gasparini, M. (2017): "El territorio y las actividades económicas”. En Rodríguez Neila, J. F. (coord.): La ciudad y sus legados históricos. Córdoba romana. Córdoba, pp. 153-206. 
